medRxiv preprint doi: https://doi.org/10.1101/2020.12.23.20248579; this version posted December 30, 2020. The copyright holder for this preprint (which was not certified by peer review) is the author/funder, who has granted medRxiv a license to display the preprint in

It is made available under a CC-BY-NC-ND 4.0 International license.

\title{
Title: A Checklist for Assessing the Methodological Quality of Concurrent tES-fMRI Studies (ContES Checklist): A Consensus Study and Statement
}

Authors: Hamed Ekhtiari ${ }^{1 \#}$, Peyman Ghobadi-Azbari²,3, Axel Thielscher ${ }^{4,5}$, Andrea Antal ${ }^{6}$, Lucia M. Li ${ }^{7,8}, \mathrm{~A}$ Duke Shereen ${ }^{9}$, Yuranny Cabral-Calderin ${ }^{10}$, Daniel Keeser ${ }^{11,12}$, Til Ole Bergmann ${ }^{13,14,15}$, Asif Jamil ${ }^{16}$, Ines R. Violante ${ }^{17}$, Jorge Almeida ${ }^{18,19}$, Marcus Meinzer ${ }^{20,21}$, Hartwig R. Siebner ${ }^{4,22,23}$, Adam J. Woods ${ }^{24}$, Charlotte J. Stagg ${ }^{25,26}$, Rany Abend $^{27}$, Daria Antonenko ${ }^{21}$, Tibor Auer ${ }^{17}$, Marc Bächinger ${ }^{28,29}$, Chris Baeken ${ }^{30,31,32}$, Helen C. Barron ${ }^{25,26}$, Henry W. Chase ${ }^{33}$, Jenny Crinion ${ }^{34}$, Abhishek Datta ${ }^{35,36}$, Matthew H. Davis ${ }^{37}$, Mohsen Ebrahimi ${ }^{3}$, Zeinab Esmaeilpour ${ }^{38}$, Brian Falcone ${ }^{39}$, Valentina Fiori ${ }^{40}$, Iman Ghodratitoostani ${ }^{41}$, Gadi Gilam ${ }^{42}$, Roland H. Grabner ${ }^{43}$, Joel D. Greenspan $^{44}$, Georg Groen ${ }^{45}$, Gesa Hartwigsen ${ }^{46}$, Tobias U. Hauser ${ }^{47,48}$, Christoph S. Herrmann ${ }^{49,50,51}$, Chi-Hung Juan $^{52,53}$, Bart Krekelberg ${ }^{54}$, Stephanie Lefebvre ${ }^{55}$, Sook-Lei Liew ${ }^{56,57,58,59}$, Kristoffer H. Madsen ${ }^{4,60}$, Rasoul Mahdavifar-Khayati ${ }^{2}$, Nastaran Malmir ${ }^{3}$, Paola Marangolo ${ }^{61,62}$, Andrew K. Martin ${ }^{20,63}$, Timothy J. Meeker ${ }^{64}$, Hossein Mohaddes Ardabilii5,66, Marius Moisa ${ }^{67}$, Davide Momi ${ }^{68}$, Beni Mulyana ${ }^{1}$, Alexander Opitz ${ }^{69}$, Natasza Orlov $^{70,71,72,73}$, Patrick Ragert ${ }^{74,75}$, Christian C. Ruff ${ }^{67}$, Giulio Ruffini ${ }^{76,77}$, Michaela Ruttorf ${ }^{78}$, Arshiya Sangchooli ${ }^{3}$, Klaus Schellhorn ${ }^{79}$, Gottfried Schlaug ${ }^{80}$, Bernhard Sehm ${ }^{75}$, Ghazaleh Soleimani ${ }^{81}$, Hosna Tavakoli, ${ }^{3,82}$, Benjamin Thompson ${ }^{83,84,85}$, Dagmar Timmann ${ }^{86}$, Aki Tsuchiyagaito ${ }^{1}$, Martin Ulrich ${ }^{45}$, Johannes Vosskuhl ${ }^{49}$, Christiane A. Weinrich $^{87,88}$, Mehran Zare-Bidoky ${ }^{3,89}$, Xiaochu Zhang ${ }^{90}$, Benedikt Zoefel ${ }^{37,91}$, Michael A. Nitsche ${ }^{16,92}$, Marom Bikson $^{38}$

1. Laureate Institute for Brain Research, Tulsa, OK, USA

2. Department of Biomedical Engineering, Shahed University, Tehran, Iran

3. Iranian National Center for Addiction Studies (INCAS), Tehran University of Medical Sciences, Tehran, Iran

4. Danish Research Centre for Magnetic Resonance, Centre for Functional and Diagnostic Imaging and Research, Copenhagen University Hospital Hvidovre, Hvidovre, Denmark

5. Department of Health Technology, Technical University of Denmark, Kgs. Lyngby, Denmark

6. Department of Neurology, University Medical Center Goettingen, Goettingen, Germany

7. Computational, Cognitive and Clinical Imaging Lab, Division of Brain Sciences, Department of Medicine, Imperial College London, UK

8. UK DRI Centre for Care Research and Technology, Imperial College London, UK

9. Advanced Science Research Center, The Graduate Center, City University of New York, New York, NY, USA

10. Research Group Neural and Environmental Rhythms, Max Planck Institute for Empirical Aesthetics, Frankfurt, Germany

11. Department of Psychiatry and Psychotherapy, University Hospital LMU Munich, Munich, Germany

12. Department of Radiology, University Hospital LMU Munich, Munich, Germany

13. Neuroimaging Center (NIC), Focus Program Translational Neuroscience (FTN), Johannes Gutenberg University Medical Center, Langenbeckstr. 1, 55131, Mainz, Germany

14. Leibniz Institute for Resilience Research, Wallstraße 7, 55122, Mainz, Germany

15. Department of Neurology and Stroke and Hertie Institute for Clinical Brain Research, Eberhard Karls University of Tübingen, Tübingen, Germany

16. Department of Psychology and Neurosciences, Leibniz Research Centre for Working Environment and Human Factors, Dortmund, Germany

17. School of Psychology, Faculty of Health and Medical Sciences, University of Surrey, Guildford, UK

18. Proaction Lab, Faculty of Psychology and Educational Sciences, University of Coimbra, Portugal

19. CINEICC, Faculty of Psychology and Educational Sciences, University of Coimbra, Portugal

20. Centre for Clinical Research (UQCCR), The University of Queensland, Brisbane, Australia

21. Department of Neurology, University Medicine Greifswald, Greifswald, Germany

22. Department of Neurology, Copenhagen University Hospital, Copenhagen, Denmark

23. Institute of Clinical Medicine, University of Copenhagen, Copenhagen, Denmark

24. Center for Cognitive Aging and Memory, McKnight Brain Institute, Department of Clinical and Health Psychology, University of Florida, Gainesville, FL, USA

NOTE: This preprint reports new research that has not been certified by peer review and should not be used to guide clinical practice. 
medRxiv preprint doi: https://doi.org/10.1101/2020.12.23.20248579; this version posted December 30, 2020. The copyright holder for this preprint (which was not certified by peer review) is the author/funder, who has granted medRxiv a license to display the preprint in It is made available under a CC-BY-NC-ND 4.0 International license .

25. Wellcome Centre for Integrative Neuroimaging, University of Oxford, FMRIB, John Radcliffe Hospital, Oxford, UK

26. Medical Research Council Brain Network Dynamics Unit, Nuffield Department of Clinical Neurosciences, University of Oxford, Mansfield Road, Oxford, UK

27. Section on Development and Affective Neuroscience, National Institute of Mental Health, Bethesda, MD, USA

28. Neural Control of Movement Lab, Department of Health Sciences and Technology, Zurich, Switzerland

29. Neuroscience Center Zurich, University of Zurich, Swiss Federal Institute of Technology Zurich, Zurich, Switzerland

30. Department of Psychiatry and Medical Psychology, University Hospital Ghent, Belgium

31. Department of Psychiatry, University Hospital Brussels, Belgium

32. Eindhoven University of Technology, Department of Electrical Engineering, the Netherlands

33. Department of Psychiatry, University of Pittsburgh School of Medicine, Pittsburgh, PA, USA

34. Institute of Cognitive Neuroscience, University College London, London, UK

35. Research and Development, Soterix Medical, New York, USA

36. The City College of the City University of New York, New York, USA

37. MRC Cognition and Brain Sciences Unit, University of Cambridge, Cambridge, UK

38. Department of Biomedical Engineering, The City College of New York of CUNY, New York, NY, USA

39. Northrop Grumman Company, Mission Systems, Falls Church, VA, United States

40. Department of Clinical and Behavioral Neurology, IRCCS Santa Lucia Foundation, Rome, Italy

41. Neurocognitive Engineering Laboratory (NEL), Center for Mathematical Sciences Applied to Industry, Institute of Mathematical and Computer Sciences, University of Sao Paulo, Brazil

42. Systems Neuroscience and Pain Laboratory, Division of Pain Medicine, Department of Anesthesiology, Perioperative, and Pain Medicine, School of Medicine, Stanford University, Palo Alto, CA, USA

43. Educational Neuroscience, Institute of Psychology, University of Graz, Austria

44. Department of Neural and Pain Sciences, University of Maryland School of Dentistry, Baltimore, MD, USA

45. Department of Psychiatry, University of Ulm, Ulm, Germany

46. Lise Meitner Research Group Cognition and Plasticity, Max Planck Institute for Human Cognitive and Brain Sciences, Leipzig, Germany

47. Max Planck University College London Centre for Computational Psychiatry and Ageing Research, University College London, London, UK

48. Wellcome Centre for Human Neuroimaging, University College London, London, UK

49. Experimental Psychology Lab, Cluster of Excellence "Hearing4all", European Medical School, University of Oldenburg, Oldenburg, Germany

50. Neuroimaging Unit, European Medical School, University of Oldenburg, Oldenburg, Germany

51. Research Centre Neurosensory Science, University of Oldenburg, Oldenburg, Germany

52. Institute of Cognitive Neuroscience, National Central University, Taoyuan, Taiwan

53. Brain Research Center, National Central University, Taoyuan, Taiwan

54. Center for Molecular and Behavioral Neuroscience, Rutgers University-Newark, Newark, New Jersey, USA

55. Translational Research Centre, University Hospital of Psychiatry, University of Bern, Bern, Switzerland

56. Chan Division of Occupational Science and Occupational Therapy, University of Southern California, Los Angeles, California, USA

57. Department of Neurology, USC Stevens Neuroimaging and Informatics Institute, Keck School of Medicine, University of Southern California, Los Angeles, California, USA

58. Department of Biomedical Engineering, University of Southern California, Los Angeles, California, USA

59. Neuroscience Graduate Program, University of Southern California, Los Angeles, California, USA

60. Department of Applied Mathematics and Computer Science, Technical University of Denmark, Kgs. Lyngby, Denmark

61. Department of Humanities Studies, University Federico II, Naples, Italy 
medRxiv preprint doi: https://doi.org/10.1101/2020.12.23.20248579; this version posted December 30, 2020. The copyright holder for this preprint (which was not certified by peer review) is the author/funder, who has granted medRxiv a license to display the preprint in It is made available under a CC-BY-NC-ND 4.0 International license .

62. Aphasia Research Lab, IRCCS Santa Lucia Foundation, Rome, Italy

63. Department of Psychology, University of Kent, Canterbury, UK

64. Department of Neurosurgery, Johns Hopkins University, Baltimore, Maryland

65. Psychiatry and Behavioral Sciences Research Center, Ibn-e-Sina Hospital, Faculty of Medicine, Mashhad University of Medical Sciences, Mashhad, Iran

66. Student Research Committee, Faculty of Medicine, Mashhad University of Medical Sciences, Mashhad, Iran 67. Zurich Center for Neuroeconomics, Department of Economics, University of Zurich, Zurich, Switzerland 68. Department of Neuroscience, Imaging and Clinical Sciences, University of Chieti-Pescara, Chieti, Italy 69. Department of Biomedical Engineering, University of Minnesota, Minneapolis, MN, USA 70. Institute of Psychiatry, Psychology and Neuroscience, King's College London, London, UK 71. Athinoula A. Martinos Center for Biomedical Imaging, Massachusetts General Hospital, Boston, MA, USA

72. Department of Radiology, Xuanwu Hospital, Capital Medical University, Beijing, China

73. Precision Brain Imaging Lab, Medical University of South Carolina, Charleston, SC, USA

74. Institute for General Kinesiology and Exercise Science, University of Leipzig, Leipzig, Germany

75. Department of Neurology, Max Planck Institute for Human Cognitive and Brain Sciences, Leipzig, Germany

76. Neuroelectrics Corporation, Cambridge, Massachusetts, MA, USA

77. Neuroelectrics Barcelona, Barcelona, Spain

78. Computer Assisted Clinical Medicine, Medical Faculty Mannheim, Heidelberg University, Mannheim, Germany

79. neuroConn $\mathrm{GmbH}$, Ilmenau, Germany

80. Neuroimaging-Neuromodulation and Stroke Recovery Laboratory, Department of Neurology, Beth Israel Deaconess Medical Center and Baystate Medical Center, UMass Medical School, MA, USA

81. Department of Biomedical Engineering, Amirkabir University of Technology, Tehran, Iran

82. Department of Cognitive Psychology, Institute for Cognitive Sciences Studies, Tehran, Iran

83. School of Optometry and Vision Science, University of Auckland, Auckland, New Zealand

84. School of Optometry and Vision Science, University of Waterloo, Ontario, Canada

85. Centre for Eye and Vision Research, Hong Kong, Hong Kong

86. Department of Neurology, Essen University Hospital, University of Duisburg-Essen, Essen, Germany

87. Department of Cognitive Neurology, University Medical Center Goettingen, Goettingen, Germany

88. Department of Neurology, University Medical Center Goettingen, Goettingen, Germany

89. Shahid-Sadoughi University of Medical Sciences, Yazd, Iran

90. CAS Key Laboratory of Brain Function and Disease and School of Life Sciences, Division of Life Science and Medicine, University of Science \& Technology of China, Hefei, China

91. Centre de Recherche Cerveau et Cognition (CerCo), CNRS, Toulouse, France

92. Université Toulouse III Paul Sabatier, Toulouse, France

93. Department of Neurology, University Medical Hospital Bergmannsheil, Bochum, Germany

\section{\#Corresponding Author:}

Hamed Ekhtiari, MD, PhD,

Laureate Institute for Brain Research,

6655 South Yale Ave. Tulsa, OK 74136,

Tel/fax: 918.502.5100,

email: hekhtiari@laureateinstitute.org 
medRxiv preprint doi: https://doi.org/10.1101/2020.12.23.20248579; this version posted December 30, 2020. The copyright holder for this preprint (which was not certified by peer review) is the author/funder, who has granted medRxiv a license to display the preprint in It is made available under a CC-BY-NC-ND 4.0 International license.

\begin{abstract}
Background: Low intensity transcranial electrical stimulation (tES), including alternating or direct current stimulation (tACS or tDCS), applies weak electrical stimulation to modulate brain circuits. Integration of tES with concurrent functional magnetic resonance imaging (fMRI) allows neuromodulation of brain regions while mapping network functions, therefore supporting causal studies of both brain function and tES effects. The methodology of tES-fMRI studies, including hardware and protocols, underpin any outcomes - so reporting methods in appropriate detail is required for reproducible experimental protocols. Despite the growing number of published reports, consensus-based checklists for disclosing standards of methodological details for concurrent tESfMRI studies were not previously established.

Objective: To develop a consensus-based checklist of reporting standards for concurrent tES-fMRI studies to support methodological rigor, transparency, and reproducibility (ContES Checklist).

Methods: A two-phase Delphi consensus process was conducted by a steering committee (SC) of 13 members and 49 expert panelists (EP) through the International Network of the tES-fMRI (INTF) Consortium. The process began with a preliminary checklist including essential items and additional recommendations developed by the SC based on a systematic review of 57 concurrent tES-fMRI studies published before January 1, 2020. In the revision phase, contributors were invited to comment, revise, or add items/recommendations to the initial checklist. Then, in the rating phase, contributors were asked to evaluate the importance of the 17 essential items and 42 additional recommendations in the final checklist. Furthermore, the state of methodological transparency and reproducibility within the 57 collected concurrent tES-fMRI studies was assessed with the proposed checklist.
\end{abstract}

Results: During the revision and rating phases, the EP and SC refined the checklist based on a preregistered consensus framework and agreed upon essential items and additional recommendations, which involved three categories: (1) technological factors, (2) safety and noise tests, and (3) methodological factors. The level of adherence to the checklist varied among the 57 published concurrent tES-fMRI articles, ranging from $24 \%$ to $76 \%$. On average, $53 \%$ of the checklist items were reported in a given article.

Conclusions: It is expected that the use of the ContES checklist will enhance the methodological reporting quality of future concurrent tES-fMRI studies and thus increase methodological transparency and reproducibility.

Keywords: Transcranial electrical stimulation (tES), Functional magnetic resonance imaging (fMRI), Concurrent tES fMRI, Consensus statement, ContES checklist. 
medRxiv preprint doi: https://doi.org/10.1101/2020.12.23.20248579; this version posted December 30, 2020. The copyright holder for this preprint (which was not certified by peer review) is the author/funder, who has granted medRxiv a license to display the preprint in

It is made available under a CC-BY-NC-ND 4.0 International license.

\section{Introduction}

The advent of functional neuroimaging techniques allows one to investigate the neural correlates of behavior and underlying processes. However, functional neuroimaging techniques cannot by themselves establish causal evidence for brain-behavior relationships. Non-invasive brain stimulation techniques, including low-intensity transcranial electrical stimulation (tES), can be used in combination with functional neuroimaging, such as functional magnetic resonance imaging (fMRI), to directly modulate patterns of neuronal activity and to establish causal evidence for the involvement of particular neural regions or networks in a specific behavior and cognitive process (Ashizuka et al., 2015; Baker et al., 2010; Barron et al., 2016; Clark et al., 2012; Frangou et al., 2018; Hu et al., 2017; Koolschijn et al., 2019; Ligneul et al., 2016; Mizuguchi et al., 2016; Nihonsugi et al., 2015; Sehm et al., 2013, 2012; Wang et al., 2017; Woods et al., 2014; Wu et al., 2015; Xue et al., 2012; Yang et al., 2017; Zhang et al., 2016). Over the last 20 years, low intensity tES has been used extensively to study and modulate the neural mechanisms underlying basic physiological and cognitive processes (Bachtiar et al., 2015; Bikson and Rahman, 2013; Jamil et al., 2020; Keeser et al., 2011; Kuo et al., 2016; Minhas et al., 2010; Nitsche and Paulus, 2000; Stagg and Nitsche, 2011; Zoefel et al., 2018). Initial studies combining tES with $\mathrm{fMRI}$ were limited to sequential tES-fMRI recording, which primarily provides an avenue to investigate the neural mechanisms underlying tES offline (after) effects (Almeida et al., 2017; Antal et al., 2014b; Esmaeilpour et al., 2019; GhobadiAzbari et al., 2020; Lee et al., 2019; Meeker et al., 2019; Ruttorf et al., 2019).

Over the last decade, advances in tES technology have made concurrent tES-fMRI in-principle technically feasible, thus enabling monitoring of immediate (online) tES effects. Concurrent tES-fMRI recordings poses specific technical challenges (Woods et al., 2016), however, these issues can be minimized when standard protocols are followed (Antal et al., 2014a; Esmaeilpour et al., 2019; Gbadeyan et al., 2016; Meinzer et al., 2014; Williams et al., 2017). As a "perturb-and-measure" approach (Paus, 2005), applications are rapidly diversifying such that concurrent tES-fMRI is being used increasingly as a proxy measure for local and global neuro-metabolic activity to address causal mechanistic (Bachinger et al., 2017; Gilam et al., 2018; Zoefel et al., 2018) and predictive (Abend et al., 2018; Lin et al., 2017) questions about underlying physiology and therapeutic effects.

Online integration of tES with $\mathrm{FMRI}$ recordings is however associated with technical and theoretical challenges, which include the risk of electrode heating due to the radio frequency (RF) pulses of the scanner (Lemieux et al., 1997; Saiote et al., 2013) and susceptibility-related echo-planar imaging (EPI) artifacts under the electrodes (Antal et al., 2014a, 2011). Furthermore, evidence is increasing for the significant impact of different methodological procedures on online fMRI responses to tES, including the localization of electrodes (Antal et al., 2011; Meinzer et al., 2013; Vosskuhl et al., 2016), MRI-conditional stimulator setup (Esmaeilpour et al., 2019; Meinzer et al., 2014; Williams et al., 2017), amount/type of contact medium (Woods et al., 2016), and the timing of concurrent tES within the fMRI paradigm (Cabral-Calderin et al., 2016; Li et al., 2019a). Given the variability in fMRI responses to tES, as well as tolerability/safety/noise concerns and methodological variations, there is an urgent need to clearly and systematically plan, measure, report, and control as many of these methodological factors as possible. In order to ensure a robust interpretation of the data and to increase the potential for future replication, a reporting guideline and checklist is required. Methodological checklists not only improve the transparent reporting of study methodology, and quality of data collection analysis, but also reduce design and reporting biases, factors with clear implications for future interpretation and use of the data. These checklists could also assist peer 
medRxiv preprint doi: https://doi.org/10.1101/2020.12.23.20248579; this version posted December 30, 2020. The copyright holder for this preprint (which was not certified by peer review) is the author/funder, who has granted medRxiv a license to display the preprint in It is made available under a CC-BY-NC-ND 4.0 International license.

review and critical appraisal of the research methodology (Baker, 2017; Buch et al., 2017; Chipchase et al., 2012).

A limited number of methodological checklists are available in the field of human brain mapping for transcranial magnetic stimulation (TMS) studies (Chipchase et al., 2012), tDCS studies (Buch et al., 2017), and MRI/fMRI studies (Nichols et al., 2017; Poldrack et al., 2008). One of the most well-known checklists in the field of human brain mapping is the COBIDAS statement which was developed to provide an evidence-based minimum set of recommendations to prepare best practices for data analysis, result reporting, algorithms, and data sharing in neuroimaging research in order to promote transparency, reliability, and collaboration (Nichols et al., 2017). Given the potential for variability of the neural responses elicited by tES and the growing number of concurrent tES-fMRI studies, guidelines on factors that should be reported and/or controlled in concurrent tES-fMRI studies are essential to ensure that research findings are correctly interpreted and are reproducible (Baker, 2016). Also, to facilitate meta-analyses, studies should be consistent in both their methodologies and reporting practice. Hence, we aimed to address these issues by conducting a Delphi study to reach a consensus on the essential items that are mandatory to be reported or recommendations that should be considered when reporting a concurrent tES-fMRI study (ContES Checklist).

\section{Research Methodology}

The flowchart of the Delphi method adapted for this study is illustrated in Figure 1. The Delphi technique is a questionnaire-based approach designed to facilitate reaching a consensus, based on the fundamental principles of purposive sampling of experts in the field of interest, panelist anonymity, iterative questionnaire presentation, and feedback of statistical analysis (Hsu and Sandford, 2007; Keeney et al., 2001; Vernon and Vernon, 2009). This study was designed, implemented, and coordinated within the international network of tES-fMRI (INTF) and a steering committee (SC) that supervised the process of checklist development, data analysis, and determining the initial criteria for item consensus and survey termination.

The development of the ContES checklist using the Delphi technique involved the following steps: (1) formation of the SC, (2) selection of the expert panel (EP), (3) checklist development and revision, and (4) data collection and analysis.

\subsection{Steering Committee (SC)}

The role of the SC, comprising Jorge Almeida, Andrea Antal, Marom Bikson, Hamed Ekhtiari, Lucia M. Li, Marcus Meinzer, Michael Nitsche, Duke Shereen, Hartwig Siebner, Charlotte Stagg, Axel Thielscher, Ines Violante, and Adam Woods, was to determine the aim of the research, produce items and select additional experts for the Delphi process. Peyman Ghobadi-Azbari served as the Delphi facilitator to implement the preregistered methods within and between the SC and expert panel (EP). The SC grew out of the INTF collaborative group after a series of webinars (28 March 2019, 27 June 2019, and 26 September 2019; recorded videos of the webinars are available on the INTF YouTube channel https://youtube.com/channel/UCKcEYDmyqTipDW7OzuoVSIg), in which considerable heterogeneities of technical/methodological aspects in studies combining tES with fMRI were discussed along with strategies to help to bridge respective knowledge gaps, and reduce heterogeneities. 
medRxiv preprint doi: https://doi.org/10.1101/2020.12.23.20248579; this version posted December 30, 2020. The copyright holder for this preprint (which was not certified by peer review) is the author/funder, who has granted medRxiv a license to display the preprint in It is made available under a CC-BY-NC-ND 4.0 International license.

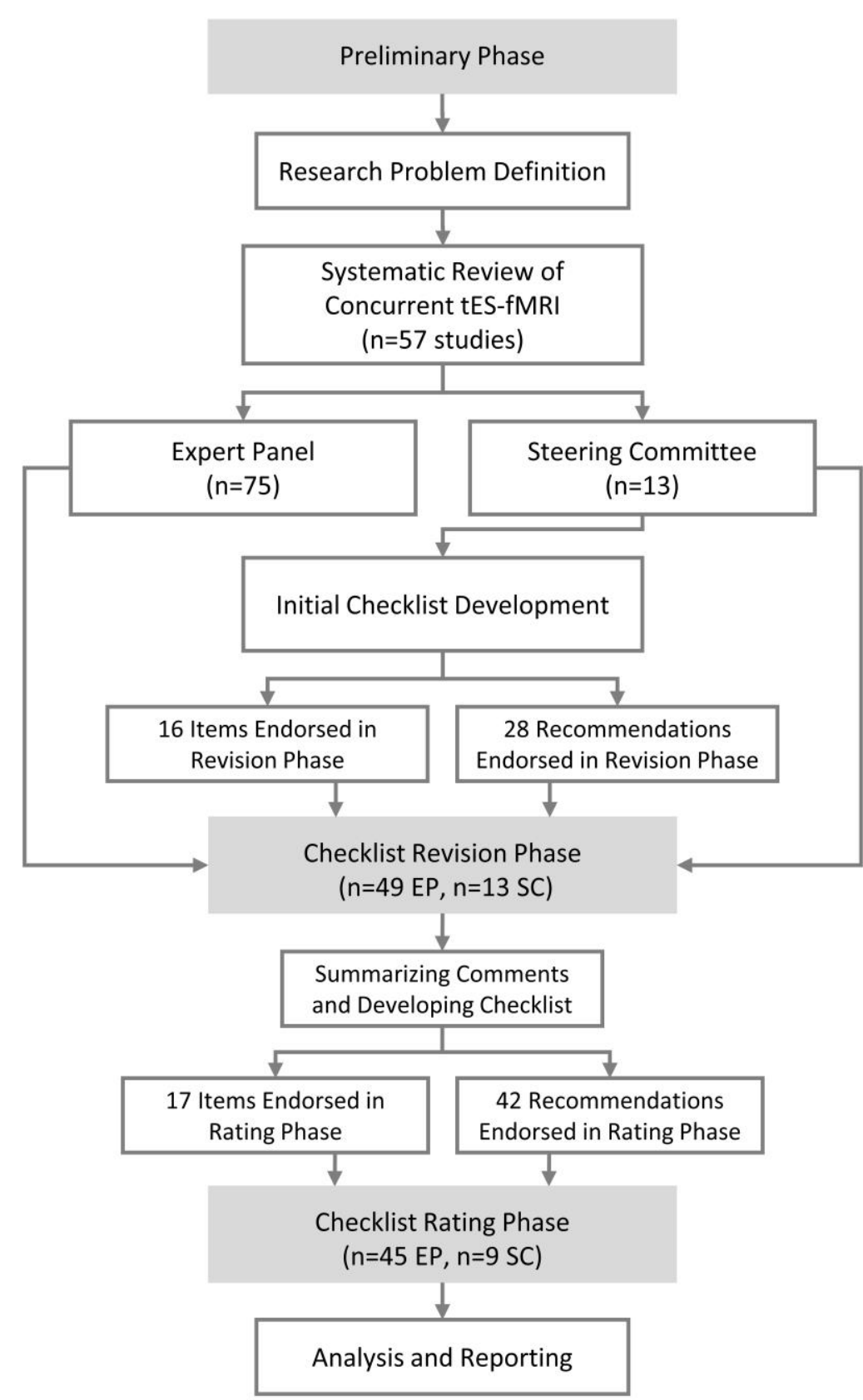

Figure 1| Flowchart diagram of the Delphi process to develop the checklist.

\subsection{Expert Panel (EP)}

The project involved the recruitment of a group of experts based on a systematic review of 57 concurrent tES-fMRI studies (published before January $1^{\text {st }}, 2020$ ). We reviewed the concurrent tESfMRI literature in the PubMed research database from inception up to January 1, 2020 to select evidence based concurrent tES-fMRI studies and experts who conducted those studies. Additional details of our systematic review criteria are provided in the Preferred Reporting Items for Systematic Reviews and Meta-Analyses (PRISMA) flow chart (Supplementary Figure 1). The search included the terms (tDCS OR transcranial direct current stimulation OR tACS OR transcranial alternating current stimulation) AND (functional magnetic resonance imaging OR fMRI OR functional MRI OR fCMRI OR functional connectivity MRI OR rsfMRI OR resting-state $f M R I)$. Fifty-seven articles were selected based on the PRISMA. The inclusion criteria used to invite the experts included being the first, last or corresponding author in at least one of the 57 published studies in the field. In addition, the 
medRxiv preprint doi: https://doi.org/10.1101/2020.12.23.20248579; this version posted December 30, 2020. The copyright holder for this preprint (which was not certified by peer review) is the author/funder, who has granted medRxiv a license to display the preprint in It is made available under a CC-BY-NC-ND 4.0 International license.

members of the SC were asked to nominate additional experts in the field of concurrent tES-fMRI to join the EP. All SC members agreed on the list of experts before the invitation process was started. Potential candidates for the EP based on the above-mentioned inclusion criteria $(n=54)$ were invited to participate in the Delphi study using the contact information provided in each publication (the email address of the respective contributor). Furthermore, the committee invited 21 additional experts to join the EP. The final EP included 75 potential candidates with expertise across a range of backgrounds (i.e., medicine, neuroscience, biomedical and electrical engineering) and geographical areas (USA, UK, Germany, Denmark, Iran, and Canada). Invitees were asked to accept to contribute to a maximum of three iterations of the consensus-based checklist. Over $65 \%$ of the invitees (49 experts) accepted to join the EP.

\subsection{Checklist Development Phase}

The checklist aimed to facilitate an in-depth consensus among the tES-fMRI experts regarding the technical/methodological aspects necessary to be followed and reported to safely and successfully perform acquisition of $\mathrm{FMRI}$ during tES delivery and to enable critical appraisal and systematic reporting of concurrent tES-fMRI studies. The initial draft of the checklist was developed based on currently available evidence in the field. The concurrent tES-fMRI studies were operationally defined as "studies that apply tES in the bore of the magnet while acquiring fMRI data during stimulation". Studies using tES-fMRI in offline or sequential approaches (i.e., imaging only before and after stimulation) to evaluate the short- and long-term after-effects of brain stimulation were not included.

As the first step of the Delphi process, an initial email circulation started within the SC by asking each SC member to suggest a list of the specific technical/methodological aspects of the interaction between $\mathrm{FMRI}$ and tES that they considered very likely to influence a concurrent $t E S-f M R I$ study and its report. Repeated responses were merged and the remaining items were thematically categorized into: technological factors, safety and noise tests, and methodological factors. The SC also suggested additional recommendations for each main item that should be considered in order to increase the quality of reporting. Following agreement on the checklist format by the SC, the checklist was tested by rating 5 sample concurrent tES-fMRI articles, with Yes/No ratings on whether the item was reported in the article or not, to ensure the checklist's objectivity and clarity. Following the pilot test, the SC reworded and/or combined items that were deemed unclear for inclusion in the revision phase. The results of each phase were summarized and displayed on the study's OSF page (https://osf.io/f9j8z/).

\subsection{Data Collection and Analysis}

\subsubsection{Checklist Revision Phase}

The consensus-based checklist was distributed among the EP and SC members. For the revision phase, contributors were sent the initial checklist email. Two consecutive follow-up reminders were emailed if a response was not received after 7 and 14 days following the initial email circulation. Contributors who completed the revision phase before the deadline were recruited in the subsequent rating phase.

The revision phase included a section on self-reporting the demographics gleaned from the EP and $\mathrm{SC}$ members and questions about their previous experiences as concurrent $t E S-f M R I$ researchers. A second section requested contributors to comment on any ambiguity or wording of the existing checklist. The revision phase included a definition of the purpose of the consensus study and an 
medRxiv preprint doi: https://doi.org/10.1101/2020.12.23.20248579; this version posted December 30, 2020. The copyright holder for this preprint (which was not certified by peer review) is the author/funder, who has granted medRxiv a license to display the preprint in It is made available under a CC-BY-NC-ND 4.0 International license.

operational definition of a prescriptive standard protocol for concurrent tES-fMRI trials, the presentation of the initial checklist, followed by the opportunity to modify and remove items/recommendations, revise the current language of the checklist, merge selected items/recommendations, and propose new items/recommendations for each subsection. Any item that was judged by the SC as an original idea was included as a new item/recommendation in the rating phase. Data obtained from the revision phase informed the $\mathrm{SC}$ in developing the finalized checklist.

\subsubsection{Checklist Rating Phase}

In the rating phase, the EP and SC members were sent a feedback document, which summarized the results of the checklist modifications. It included the clarification and correction of terminology, as well as a summary of comments. Each contributor was asked to score each item of the modified checklist. The contributors were requested to rate the 17 items based on their relative importance. The rating was 1 to 5, which was (1) not important, (2) slightly important, (3) moderately important, (4) highly important, and (5) extremely important. Contributors were also asked to review the list of 42 recommendations and indicate (Yes vs. No) whether each recommendation is crucial to be taken into account during study design and reporting.

\subsubsection{Data Analysis}

In the rating phase, the average rating and the number of responses were calculated. For the main items, the tally of scores of "extremely important", "highly important" and "moderately important" represented "essential", whereas the tally of the scores of "slightly important" and "not important" represented "non-essential". We defined consensus as $\geq 70 \%$ of respondent scorings of an item as essential, with a second, preferred level of consensus at $\geq 80 \%$ agreement. Also, for additional recommendations, all respondents rated the 42 recommendations with the scores of "Yes" or "No", as previously described. The recommendation items receiving a response of "Yes" from at least $50 \%$ of EP and SC members were defined as achieving consensus.

\subsubsection{Assessing the State of Reproducibility and Transparency in concurrent tES-fMRI studies with the ContES Checklist}

To retrospectively assess the state of reproducibility and transparency in reporting via adherence to the ContES Checklist in published concurrent tES-fMRI studies, we evaluated 57 studies using the ContES checklist. Three independent raters (HT, NM, HMA) rated adherence to the reporting checklist within these articles using the 17-items checklist. An inter-rater reliability analysis using the Fleiss' Kappa statistic was performed to assess the consistency of the raters' evaluations of concurrent tES-fMRI research in the context of the ContES checklist(Fleiss, 1971). If Fleiss's Kappa is greater than 0.8, the accuracy of the inter-rater reliability indicates "Almost Perfect Agreement" (Landis and Koch, 1977).

\subsection{Ethics}

No IBR approval was required for this expert panel activity. This consensus-seeking activity neither involved novel experimental work nor novel analyses of existing experimental data, but relied entirely on mutual exchange of expertise and opinions within the panel taking into account all existing peer-reviewed scientific studies on concurrent tES-fMRI. Potential contributors were informed that by responding to the invitation letter, they were deemed to have consented to take 
medRxiv preprint doi: https://doi.org/10.1101/2020.12.23.20248579; this version posted December 30, 2020. The copyright holder for this preprint (which was not certified by peer review) is the author/funder, who has granted medRxiv a license to display the preprint in It is made available under a CC-BY-NC-ND 4.0 International license .

part in the Delphi study and that their de-identified responses are included in all analyses. All named contributors also provided consent to be acknowledged in this paper.

\section{Results}

\subsection{Characteristics of The SC and EP and Response Rates}

The characteristics of the SC and EP are presented in Table 1. The SC and EP had a mean (SD) of 8.67 (5.4) and 5.54 (2.7) years of experience in tES-fMRI research, respectively. They represented a range of professions and academic disciplines including neuroscientists (49\% EP, 85\% SC), cognitive scientists (16\% EP, $8 \% \mathrm{SC}$ ), psychiatrists (10\% EP, 0\% SC), and psychologists (10\% EP, 0\% SC). Their professional settings were primarily universities (59\% EP, 69\% SC), hospitals (18\% EP, 8\% SC), university hospitals (0\% EP, 8\% SC), independent research institutes (6\% EP, 15\% SC), and businesses/industries ( $6 \% \mathrm{EP}, 0 \% \mathrm{SC}$ ), and the most commonly held academic degrees were PhD (76\% EP, 69\% SC), MD-PhD (6\% EP, 15\% SC), and MD (4\% EP, 15\% SC). From the 75 experts invited to participate in the Delphi study, along with 13 SC members, 62 (70.4\%) contributors completed the revision phase of the Delphi questionnaire. Retention was very high, with 54 (87.1\%) revision phase contributors also completing the rating phase.

Table 1| Characteristics of steering committee and experts.

\begin{tabular}{|c|c|c|}
\hline \multirow{2}{*}{ Demographic Variables } & \multicolumn{2}{|c|}{ Frequency (\%) } \\
\hline & Steering Committee & Expert \\
\hline \multicolumn{3}{|l|}{ Gender } \\
\hline Male & $8(62 \%)$ & 29 (59\%) \\
\hline Female & $4(31 \%)$ & $11(22 \%)$ \\
\hline Other & $1(8 \%)$ & $5(10 \%)$ \\
\hline No response & $0(0 \%)$ & $4(8 \%)$ \\
\hline \multicolumn{3}{|l|}{ Age (years) } \\
\hline $30-40$ & $4(31 \%)$ & $23(47 \%)$ \\
\hline $40-50$ & $6(46 \%)$ & $10(20 \%)$ \\
\hline$\geq 50$ & $3(23 \%)$ & $10(20 \%)$ \\
\hline No response & $0(0 \%)$ & $6(12 \%)$ \\
\hline \multicolumn{3}{|l|}{ Highest Academic Degree } \\
\hline Master of Science & $0(0 \%)$ & $3(6 \%)$ \\
\hline Doctor of Medicine & $2(15 \%)$ & $2(4 \%)$ \\
\hline Doctor of Philosophy & $9(69 \%)$ & $37(76 \%)$ \\
\hline Doctor of Medicine/Philosophy & $2(15 \%)$ & $3(6 \%)$ \\
\hline No response & $0(0 \%)$ & $4(8 \%)$ \\
\hline \multicolumn{3}{|l|}{ Country of Residence } \\
\hline Austria & $0(0 \%)$ & $1(2 \%)$ \\
\hline Belgium & $0(0 \%)$ & $1(2 \%)$ \\
\hline Brazil & $0(0 \%)$ & $1(2 \%)$ \\
\hline Canada & $0(0 \%)$ & $1(2 \%)$ \\
\hline China & $0(0 \%)$ & $1(2 \%)$ \\
\hline Denmark & $2(15 \%)$ & $1(2 \%)$ \\
\hline France & $0(0 \%)$ & 1 (2\%) \\
\hline Germany & $3(23 \%)$ & $14(29 \%)$ \\
\hline
\end{tabular}


medRxiv preprint doi: https://doi.org/10.1101/2020.12.23.20248579; this version posted December 30, 2020. The copyright holder for this preprint (which was not certified by peer review) is the author/funder, who has granted medRxiv a license to display the preprint in It is made available under a CC-BY-NC-ND 4.0 International license.

Italy
Portugal
Switzerland
Taiwan
United Kingdom
United States
No response

$0(0 \%)$
$1(8 \%)$
$0(0 \%)$
$0(0 \%)$
$3(23 \%)$
$4(31 \%)$
$0(0 \%)$

$3(6 \%)$

$0(0 \%)$

$3(6 \%)$

$1(2 \%)$

$5(10 \%)$

$12(24 \%)$

$4(8 \%)$

Primary Field of Research

Cognitive Science

$\begin{array}{cc}1(8 \%) & 8(16 \%) \\ 11(84 \%) & 24(49 \%) \\ 0(0 \%) & 5(10 \%) \\ 0(0 \%) & 5(10 \%) \\ 1(8 \%) & 3(6 \%) \\ 0(0 \%) & 4(8 \%)\end{array}$

Neuroscience

$4(49 \%)$

Psychiatry

(10\%)

Psychology

$3(6 \%)$

No response

$0(0 \%)$

$3(6 \%)$

Business/Industry

$1(8 \%)$

$9(18 \%)$

Independent Research Institute

$2(15 \%)$

$3(6 \%)$

University

$9(69 \%)$

29 (59\%)

Hospital and University

$1(8 \%)$

$0(0 \%)$

Others

$0(0 \%)$

$1(2 \%)$

No response

$0(0 \%)$

$4(8 \%)$

Length of Time Spent in tES or fMRI Research
(Years)

Less than 5

$0(0 \%)$

$1(2 \%)$

$5-10$

$3(23 \%)$

$10(20 \%)$

10-20

$5(38 \%)$

$25(51 \%)$

$\geq 20$

$4(31 \%)$

$9(18 \%)$

No response

$1(8 \%)$

$4(8 \%)$

Length of Time Spent in tES-fMRI Research

(Years)

$\begin{array}{lcc}\text { Less than } 5 & 2(15 \%) & 16(33 \%) \\ 5-10 & 7(54 \%) & 23(47 \%) \\ 10-20 & 2(15 \%) & 4(8 \%) \\ \geq 20 & 1(8 \%) & 0(0 \%) \\ \text { No response } & 1(8 \%) & 6(12 \%)\end{array}$

\subsection{Results of the Delphi Process}

\subsubsection{Checklist Development Phase}

Four members of the SC (ADS, IRV, JA, HE) produced an initial list of items for the overall structure of the checklist based on suggestions derived from the concurrent tES-fMRI studies literature. After the discussions within the SC, the checklist was expanded from 14 items to 16 items. Thus, for the revision phase, 9 items in the Technological Factors category, 4 items in the Safety and Noise Tests category, and 3 items in the Methodological Factors category were provided within the checklist. Furthermore, an "Additional Recommendations" column was added to the ContES checklist by the SC with 28 additional recommendations for experimental parameters and practices. These additional 
medRxiv preprint doi: https://doi.org/10.1101/2020.12.23.20248579; this version posted December 30, 2020. The copyright holder for this preprint (which was not certified by peer review) is the author/funder, who has granted medRxiv a license to display the preprint in

It is made available under a CC-BY-NC-ND 4.0 International license .

recommendations provide guidance to the requirements for adequate, and appropriately documented simultaneous conduction of $\mathrm{FMRI}$ and tES.

\subsubsection{Checklist Revision Phase}

In the revision phase, one item was added to the ContES checklist (tES-fMRI Setting Test - Subjective Intolerance Reporting). The additional recommendations were expanded by the contributors from 28 items to 42 items. The final checklist includes 9 items and 19 recommendations in the Technological Factors category, 5 items and 12 recommendations in the Safety and Noise Tests category, 3 items and 9 recommendations in the Methodological Factors category as well as 2 general recommendations. Different versions of the checklist in its development process are provided by the study's OSF page (https://osf.io/f9j8z/).

\author{
Category 1: Technological Factors \\ 1.1. Manufacturer of MR Conditional Stimulator \\ 1.2. MR Conditional Electrode Details \\ 1.3. Electrode Positioning \\ 1.4. MR Conditional Skin-Electrode Interface \\ 1.5. Amount of Contact Medium (Paste/Gel/Electrolyte) $†, \ddagger$ \\ 1.6. Electrode Placement Visualization $\dagger$ \\ 1.7. RF Filter \\ 1.8. Wire Routing Pattern $\dagger$ \\ 1.9. tES-fMRI Machine Synchronization/Communication \\ Category 2: Safety and Noise Tests \\ 2.1. MR Conditionality Specifics for tES Setting \\ 2.2. tES-fMRI Setting Test - Safety Testing \\ 2.3. tES-fMRI Setting Test - Subjective Intolerance Reporting \\ 2.4. tES-fMRI Setting Test - Noise/Artifact \\ 2.5. Impedance Testing \\ Category 3: Methodological Factors \\ 3.1. Concurrent tES-fMRI Timing \\ 3.2. Imaging Session Timing \\ 3.3. tES Experience Report
}

Extremely Important

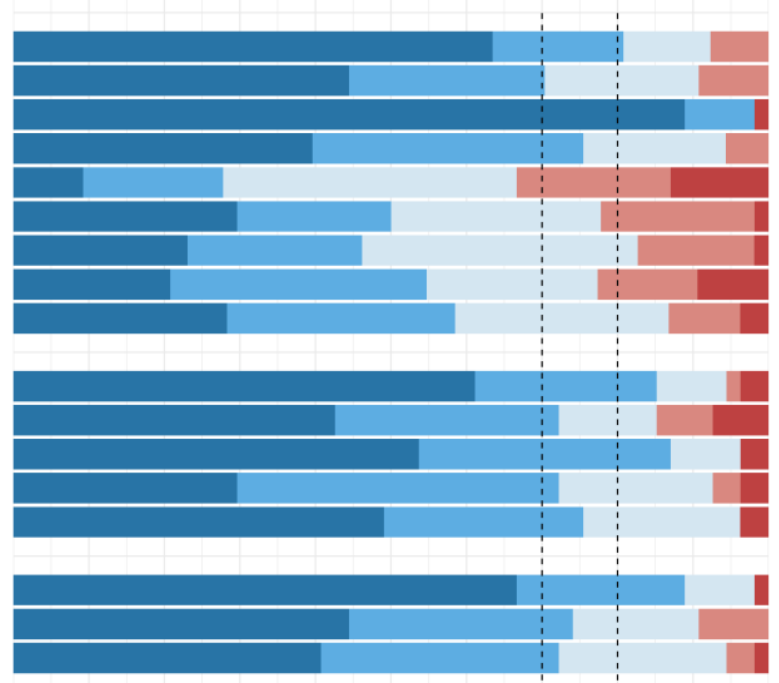

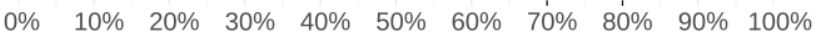

Moderately Important $\quad$ Slightly Important $\quad$ Not Important

Figure 2| Collected responses from contributors regarding the importance of the main items (rating phase). This figure depicts the rating of the checklist items by 54 respondents in the rating phase. Each item was rated from 1-5 (not important-extremely important). 14 items reached the $80 \%$ threshold (rated as either moderately, highly, or extremely important by more than $80 \%$ of the respondents). The items that did not reach this threshold are marked with "†"). 16 items reached the $70 \%$ threshold (rated as either moderately, highly, or extremely important by more than $70 \%$ of the respondents). The one item, which did not reach this threshold is marked with "¥". Full text of the items is provided in Tables 2-4.

\subsubsection{Checklist Rating Phase}

The collected responses of the rating phase are shown in Figures 2 and 3, and also in Tables 2, 3 and 4. Respondents had a high rate of agreement about most of the checklist items. However, three items (marked with + in Figure 2): Amount of Contact Medium (Paste/Gel/Electrolyte), Electrode Placement Visualization, and Wire Routing Pattern did not reach the $80 \%$ consensus threshold (rated as either moderately, highly, or extremely important by more than $80 \%$ of the respondents). Of these, one item, Amount of Contact Medium (Paste/Gel/Electrolyte), did not reach the $\geq 70 \%$ consensus (marked with $¥$ in Figure 2 and Supplementary Table 1). However, the draft ContES checklist met the consensus level for all 17 items with a $65 \%$ threshold. The rating phase included also scoring of each of the additional recommended items by the scoring choices of Yes and No. The results showed that $38(90 \%)$ of the recommendations reached the $50 \%$ threshold (rated as Yes by more than $50 \%$ of the contributors), but the following 4 recommendations did not (10\%) (Figure 3): 
medRxiv preprint doi: https://doi.org/10.1101/2020.12.23.20248579; this version posted December 30, 2020. The copyright holder for this preprint (which was not certified by peer review) is the author/funder, who has granted medRxiv a license to display the preprint in

It is made available under a CC-BY-NC-ND 4.0 International license .

Control of Amount of Contact Medium, Attenuation Characteristic of RF Filter, Restrictions/Regulations for RF Filtering Method, and Restrictions/Regulations for Wire Routing Pattern.

The ratings of the items and recommendations of the ContES checklist are outlined in Tables 2-4. The full version of the ContES checklist that includes 17 essential items and 42 additional recommendations and a short version that includes essential items only are provided in Supplementary Tables 1 to 4 to be used by authors and reviewers. The reporting items that did not meet the $70 \%$ and $80 \%$ thresholds and additional recommendations that did not meet the $50 \%$ thresholds are marked in the final checklist. Based on this information, researchers can decide to choose more stringent or more liberal thresholds when using the checklist.

Category 1: Technological Factors

1.2.1. MR Conditional Electrode Conductive Properties

1.3.1. Electrode Positioning for Improving Reproducibility

1.3.2. Level of Localization of Electrode Position

1.3.3. Method for Individualized Electrode Positioning

1.3.4. Reproducibility of Localization of Electrode Position in Multiple tES Sessions

1.3.5. Securing Electrode Placement inside Scanner

1.3.6. Electrode Cable Placement inside Scanner

1.3.7. Post hoc Validation of Electrode Positioning

1.4.1. MR Conditional Skin Electrode Interface Visualization

1.4.2. MR Conditional Skin Electrode Interface Control

1.5.1. Control of Amount of Contact Medium \#

1.7.1. Attenuation Characteristic of RF Filter \#

1.7.2. Restrictions Regulations for RF Filtering Method \#

1.8.1. Cable Testing inside Scanner

1.8.2. MR Safe Cable Details

1.8.3. Securing Cables Filter Boxes during Imaging

1.8.4. Wire Routing Pattern Modifications from Manufacturer Recommendations

1.8.5. Restrictions Regulations for Wire Routing Pattern \#

1.9.1. tES MRI Synchronization

Category 2: Safety and Noise Tests

2.1.1. MR Technical Specifications

2.1.2. MR Conditionality Specifications based on tES Manufacturer Guideline

2.3.1. Safety Tests for tES fMRI Setting

2.3.1. Safety Incidents for tES fMRI Setting

2.3.1. Reasons for Subjective tES fMRI Intolerance

2.4.1. Manufacturer s Statement for Signal to Noise Ratio

2.4.2. Exclusion Criteria from Data Analysis Artifact

2.4.3. Quantification of Artifact Noise Caused by Task fMRI Devices

2.4.4. Quantification of Artifact Noise Caused by tES Setup with Pre tES fMRI

2.4.5. Image Processing Assessments for tES Induced Imaging Artifacts

2.5.1. Characteristics of Impedance Recorded

2.5.2. Current Delivered Assessment inside Scanner

Category 3: Methodological Factors

3.1.1. Schematic Diagram for Concurrent tES fMRI Timing

3.1.2. Carry Over Effects for Stimulation Condition Brain State

3.2.1. Timing of Imaging Events

3.2.2. Placement Time of tES Setup on Subject

3.2.3. Frequency Matching for tACS Studies

3.3.1. Assessment of tES Subjective Experience inside Scanner

3.3.2. Electric Current Tolerance

3.3.3. Training for Subject Convenience before tES fMRI Session

3.3.4. Subjective Experiences Questionnaires of Receiving tES inside Scanner

3.0.1. Handedness

3.0.2. Electrode Placement Verification

Yes

No

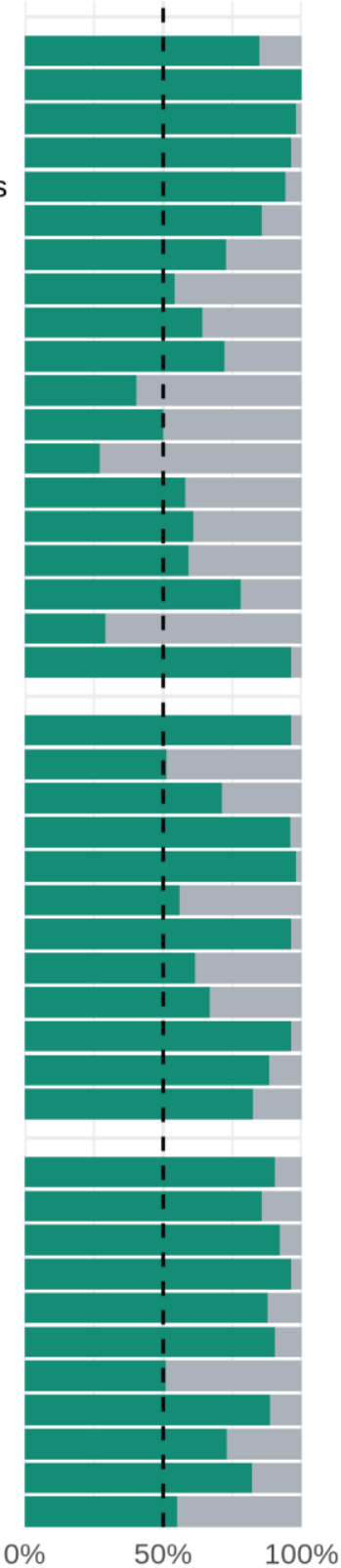

Figure 3| Collected responses of the contributors regarding the importance of recommendations (rating phase). Each additional recommendation was rated either "Yes" or "No" with respect to the question of whether it should be included as a recommendation. The recommendations rated with Yes by lower than $50 \%$ 
medRxiv preprint doi: https://doi.org/10.1101/2020.12.23.20248579; this version posted December 30, 2020. The copyright holder for this preprint (which was not certified by peer review) is the author/funder, who has granted medRxiv a license to display the preprint in

It is made available under a CC-BY-NC-ND 4.0 International license .

of the respondents are marked with "\#". Recommendations are represented by their summary in the figure. Full text of the recommendations is provided in Tables 2-4.

\subsection{Assessing the State of Adherence to the ContES Checklist}

Three independent raters evaluated the adherence of the concurrent $t E S-f M R I$ articles to the finalized reporting checklist items. The consistency of the raters' responses resulted in a Fleiss' Kappa of 0.85, indicating that the consistency is Almost Perfect Agreement (Landis and Koch, 1977). Inclusion of information about the main items of the ContES checklist varied widely, ranging from fully reported (100\%; Manufacturer of MR Conditional Stimulator, Concurrent tES-fMRI Timing, Imaging Session Timing) to rarely reported (5.3\%; MR Conditionality Specifics for tES Setting, Amount of Contact Medium). The pattern of adherence to the checklist items varied relevantly between articles, ranging from $24 \%$ to $76 \%$, averaging $53 \%$ of checklist items reported in a given article (Figure 4).

All studies (100\%) reported the Manufacturer of MR Conditional Stimulator (Item 1), and the Electrode Positioning (Item 3) was described clearly in $89 \%$ of articles, but details of the MR Conditional Electrode (Item 2) were included in only $56 \%$ of the reviewed articles. A relatively high number of papers (84\%) reported the MR Conditional Skin-Electrode Interface (Item 4), but the Amount of Contact Medium (Item 5) was mentioned less frequently (5\%). The Electrode Placement Visualization (Item 6) was shown in only $25 \%$ of the articles, and the RF Filter (Item 7) was included in $35 \%$ of the articles. The Wire Routing Pattern (Item 8 ) was described clearly in only $32 \%$ of articles, and the tES-fMRI Machine Synchronization/Communication (Item 9) was rarely described (23\%).

Only $5 \%$ of the articles reported information regarding MR Conditionality Specifics for tES Setting (Item 10). Few articles described details of the tES-fMRI setting test, ranging between 28 and $33 \%$ in Items 11-13 (33\% Safety Testing, 33\% Subjective Intolerance Reporting, 28\% Noise/Artifact). Impedance Testing (Item 14) information was included in only $28 \%$ of articles. Concurrent tES-fMRI Timing (Item 15) and the Imaging Session Timing (Item 16) were reported in all 57 articles, however tES Experience was reported less frequently (Item 17; 63\%).

a

1.1. Manufacturer of MR Conditional Stimulator

1.2. MR Conditional Electrode Details

1.3. Electrode Positioning

1.4. MR Conditional Skin-Electrode Interface

1.5. Amount of Contact Medium (Paste/Gel/Electrolyte)

1.6. Electrode Placement Visualization

1.7. RF Filter

8. Wire Routing Pattern

1. tES-fMRI Machine Synchronization/Communication Category 2: Safety and Noise Tests

2.1. MR Conditionality Specifics for tES Setting

2.2. tES-fMRI Setting Test - Safety Testing

2.3. tES-fMRI Setting Test - Subjective Intolerance Reporting

2.4. tES-fMRI Setting Test - Noise/Artifact

2.5. Impedance Testing

Category 3: Methodological Factors

3.1. Concurrent tES-fMRI Timing

3.2. Imaging Session Timing

3.3. tES Experience Report
Category 1: Technological Factors

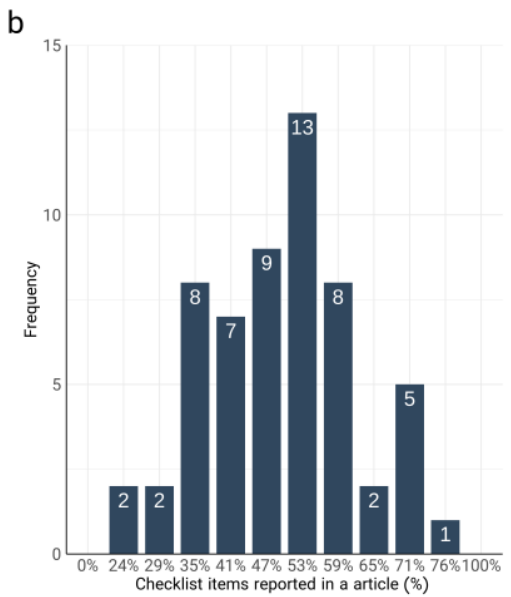

b

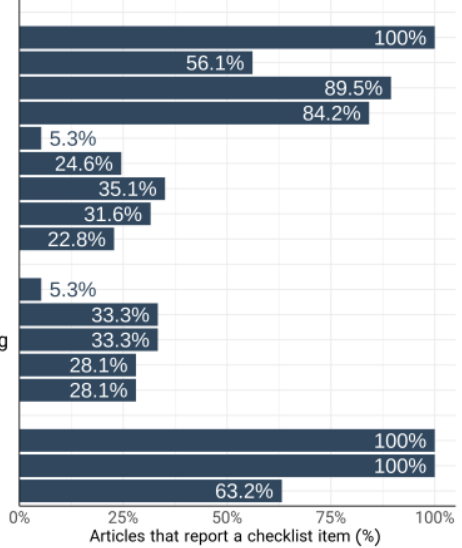

Figure 4| State of reproducibility/transparency in concurrent tES-fMRI research in the context of the ContES checklist. Assessments by 3 independent raters are based on 57 articles published in concurrent tES-fMRI research from inception up to January 1, 2020. a, Percentage of the articles that adhered to each checklist item. $\mathbf{b}$, The checklist items adhered to by the 57 articles. 
medRxiv preprint doi: https://doi.org/10.1101/2020.12.23.20248579; this version posted December 30, 2020. The copyright holder for this preprint (which was not certified by peer review) is the author/funder, who has granted medRxiv a license to display the preprint in

It is made available under a CC-BY-NC-ND 4.0 International license .

\section{Discussion}

The goal of this study was to develop a consensus-based checklist of methodological details to facilitate the evaluation of concurrent tES-fMRI studies in terms of methodological transparency and reproducibility (ContES Checklist). We successfully developed the ContES checklist to guide authors in reporting the minimum information necessary to ensure reproducibility using the 17 essential items. The 42 additional recommendations should be considered to further enhance the quality of future research in this field. This checklist should be used by editors and reviewers for critical appraisal. The checklist will also be helpful for researchers who are in the process of setting-up a concurrent tES-fMRI study. Indeed, our systematic literature review and appraisal of 57 published concurrent tES-fMRI studies revealed a general lack of sufficient information to fully reproduce critical methodological details of these studies. Overall, this checklist offers a methodological framework for understanding and replicating previous studies, and also provides journal reviewers and editors with an efficient tool to gauge and promote concurrent tES-fMRI reproducibility. Figure 5 summarizes the items which are deemed significant to be considered when conducting and reporting a concurrent tES-fMRI study.

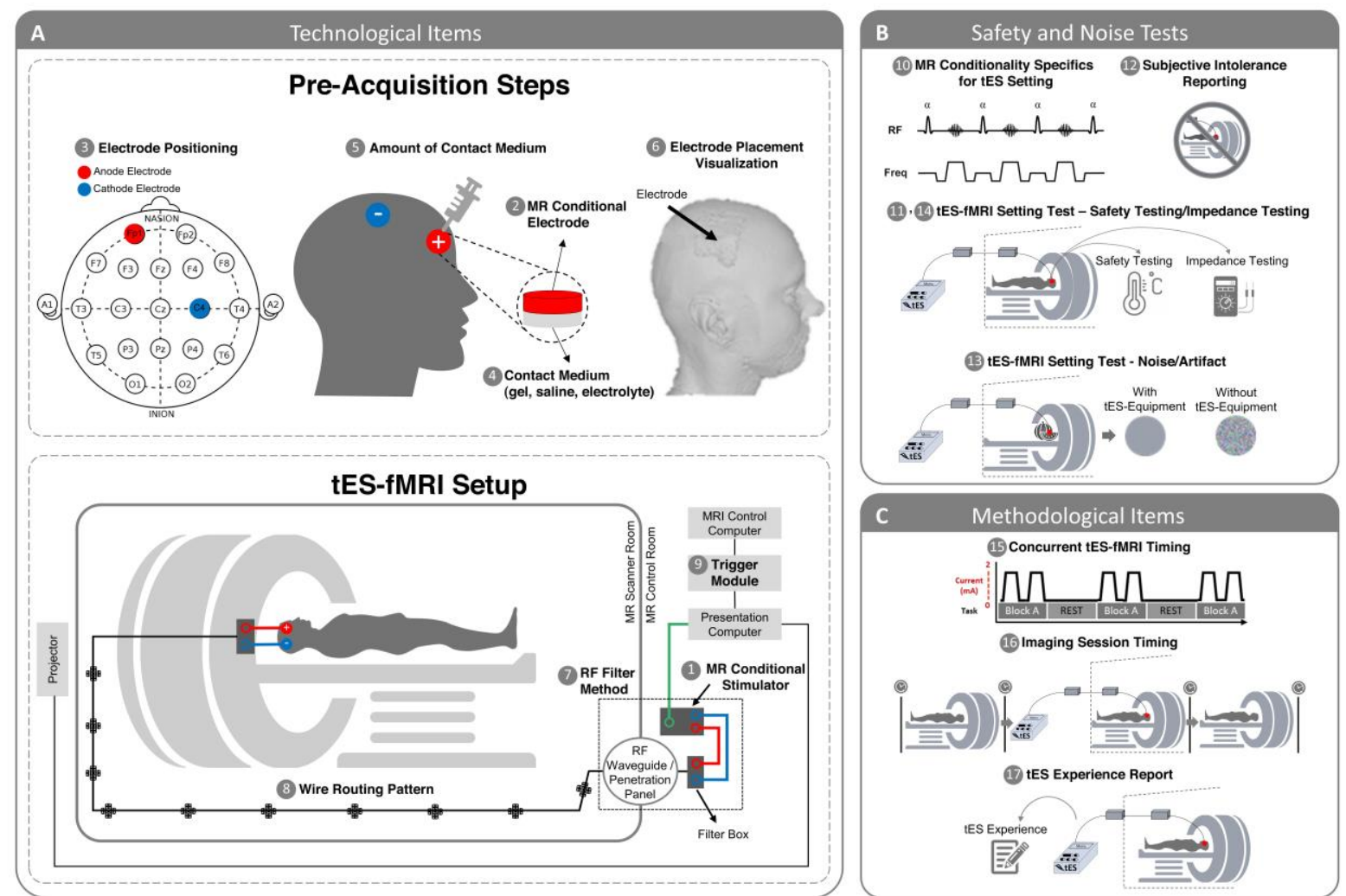

Figure 5| Scheme of the concurrent tES-fMRI approach in the context of the ContES checklist. (A) Summary of technological considerations. MR conditional stimulator (1, item 1.1) is connected to the head through RF waveguide or RF penetration panel (7, item 1.7). Box cable should be aligned with the wall of the scanner room and run parallel to the bore axis (8, item 1.8). MR conditional stimulator is connected to the outer filter box or RF band-stop filter adapter as well as to the presentation computer trigger output cable. Synchronization module (9, item 1.9) should be connected to the presentation computer as well as to the MRI control computer. Electrode positioning (3, item 1.3) is used to accurately stimulate target cortical regions and exert neuromodulatory effects. A method allowing quantification of contact medium (e.g., syringes) should be used to achieve a consistent and appropriate amount of contact medium (5, item 1.5). MR conditional skinelectrode (e.g., saline solution, conductive paste, gel) $(2$, item 1.2$)$ is used to facilitate delivery of current to the scalp (4, item 1.4). Electrode placement visualization can be used to reproducibly center each electrode on the head so that intrascanner stimulation allows verification of correct positioning of the electrodes on the head 
medRxiv preprint doi: https://doi.org/10.1101/2020.12.23.20248579; this version posted December 30, 2020. The copyright holder for this preprint (which was not certified by peer review) is the author/funder, who has granted medRxiv a license to display the preprint in

It is made available under a CC-BY-NC-ND 4.0 International license.

(6, item 1.6). (B) Summary of safety considerations. MR Conditionality Specifics for tES Setting include the technical specifications of the MR scanner, the applied fMRI sequences, and the used tES settings and configuration to fall within the specifics of MR conditionality based on tES manufacturer guideline (10, item 2.1). The Safety of the tES-fMRI Setting includes electrode temperature testing, electric current tolerance testing, etc. with real human subjects or phantoms (11, item 2.2). tES-fMRI Setting Test - Subjective Intolerance Reporting shows the number of cases that have not tolerated the tES-fMRI session (12, item 2.3). tES-fMRI Setting Test - Noise/Artifact shows the noise/artifact induced by the tES setting in the fMRI signal with real human subjects or phantoms before starting the study (13, item 2.4). The impedance is monitored before entering the scanner room and/or in the scanner room and/or inside the scanner and/or during scanning (14, item 2.5). (C) Summary of methodological considerations. Concurrent tES-fMRI Timing shows the timing of concurrent tES within the fMRI paradigm (15, item 3.1). Imaging Session Timing shows the imaging events before and after concurrent $t E S-f M R I$ and respective sequences (16, item 3.2). tES Experience Report includes the assessment of the subjective experience of receiving tES inside the scanner $(17$, item 3.3).

\subsection{Technological Factors}

The technical features of the stimulator and accessories, including set-up on the subject's head and configuration inside the scanner, underpin rigor and reproducibility - which in turn informs how these elements should be reported. Manufacturer make and model should be reported but the degree to which this satisfies items on the checklist varies. For example, while the material composition of an electrode may not always be explicitly specified, indicating a unique electrode part number would allow reproduction and referencing to other documentation. For other items, the amount of details given beyond the part number can vary dependent on the specific approach. For example, the thickness of paste is determined by the operator (set-up) for large pad electrodes, while thickness is controlled by the electrode holder for HD electrodes. The item number does however not explain set-up details such as cable arrangements or ad-hoc steps to support electrode positioning. These aspects are important to state. The degree to which prior papers can be referenced for these methodological details (e.g., "we applied tES-fMRI used methods as reported in these other references") should be qualified. Our analysis suggests that to date only a limited number of papers documented these details in sufficient detail. To the extent these technical factors underpin reproducibility, expanding on them in any given publication supports rigor.

Electrodes used for stimulation inside the MR environment need to be at least MR conditional. Manufacturer and model details, electrode size and shape, as well as materials and conductive properties of electrodes (conductive polymer, $\mathrm{Ag} / \mathrm{AgCl}$, etc.), connectors (often residually ferromagnetic), cables, and other conductive materials (e.g., a specific brand of electrode paste and $\mathrm{NaCl}$ concentration) need to be provided. The relevant item in the checklist was considered highly important (item 1.2, average rating score: 4.06) and the inclusion of the additional recommendation was recommended by $85 \%$ of the contributors (recommendation 1.2.1). Also, the position of the connector on the electrode should be reported, as it can significantly influence the homogeneity of current distribution within the electrode (Saturnino et al., 2015). As revealed by concurrent tDCSMEG experiments (Marshall et al., 2016), some conductive polymer (rubber) electrodes are magnetized, possibly during the production process, while others from the same brand are not. It remains to be determined whether this property is also related to MR imaging artifacts.

Electrode positions and size are crucial parameters which determine the distribution of current flow in the brain tissue. It is therefore recommended unanimously by the experts to report this information (item 1.3, average rating score: 4.83 ) as precisely as possible. It should be distinguished between how the intended montage is determined and how this is practically implemented. The former may be based on the literature, on theoretical considerations, or dedicated E-field modeling in generic or personalized head models, whereas the latter may involve TMS hotspot-search (for 
medRxiv preprint doi: https://doi.org/10.1101/2020.12.23.20248579; this version posted December 30, 2020. The copyright holder for this preprint (which was not certified by peer review) is the author/funder, who has granted medRxiv a license to display the preprint in

It is made available under a CC-BY-NC-ND 4.0 International license .

M1), 10-20 EEG system head measurements, or MR-based neuronavigation. The reported details should also include the method of electrode positioning (e.g., with or without EEG cap), the position of the electrode center, and if applicable, its orientation in case of non-circularly shaped electrodes. Instead of "the electrode was positioned on the left $\mathrm{M} 1$ " one would preferably state, for example, that "the electrode was centered on the FDI motor hotspot as determined by TMS, with the longer sides of the $7 \times 5 \mathrm{~cm}^{2}$ rectangular electrode pointing into anteromedial and posterolateral direction, respectively, and the connector inserted at the center of the electrode pointing towards one shorter side into anteromedial direction". If MRI-based head modeling was used, it should be stated whether electrode position had been determined based on individual anatomy or a group template, and how electrode positioning was performed, e.g., using a neuronavigation system or EEG 10-20 coordinates. For MR-based neuronavigation, also MNI coordinates may be reported for electrode centers and/or corners. In case of multi-session experiments, measures taken to ensure consistency of electrode placement across sessions have to be described, such as co-registration of stimulation electrodes with the individual MRI with neuronavigation or the use of EEG caps and/or the 10-20 system (Padberg et al., 2017). The accuracy of the stimulation montage can only be judged if this information is provided and the detailed information further allows post-hoc current modeling and replication studies.

It is also recommended to report the position of electrodes and, in particular, how the cables are directed (intertwined or separated) relative to the MR head coil, as well as information on how electrodes were affixed to the head in the $M R$, and how the head was stabilized to prevent movement of electrodes relative to either head or MR coil during recordings to prevent discomfort, impedance issues, and imaging artifacts, respectively. A post-hoc validation of electrode positions can also be achieved by the acquisition of anatomical images with the stimulation electrodes in place, even though such images might not be easy to use for E-field modelling itself (due to the challenges of segmentation between the electrodes and skin), for which anatomical images without electrodes (and related artifacts) are preferred.

For the sake of reproducibility, it is also important to provide a proper visualization of electrode position (item 1.6, average rating score: 3.56 ), which may be a photo, a sufficiently detailed schematic figure, or, preferably, the precisely modeled representations on a 3D-rendered head surface as provided by E-field modeling software, such as SimNIBS (Thielscher et al., 2015) or ROAST (Huang et al., 2019). Besides the electrode position itself, it is also considered highly important to provide visual information (a photo or sufficiently detailed schematic figure) regarding the skinelectrode interface (item 1.4, average rating score: 4.09), i.e., which conducting medium was used (e.g., gel/paste or saline solution with sponges), how contact with the skin was ensured if the hair was in between, as well as measures taken to restrict the location of the contact medium to control the effective size of the stimulation surface and prevent short circuits. While the amount of conductive medium (volume of saline solution or thickness of the layer of electrode paste) was rated of medium importance (item 1.5, average rating score: 2.91), this information, together with the evenness of its distribution across the electrode surface, is relevant for the impedance as well as the current distribution in the skin (and potentially the brain). It can, however, be very difficult in practice to control this variable, given that gel is squeezed between electrode and head and saline solution flows away or evaporates, and it is thus helpful to also report potential countermeasures taken to control or measure this influence. In any case, electrode impedances should be measured directly before and after the experiment and be reported. 
medRxiv preprint doi: https://doi.org/10.1101/2020.12.23.20248579; this version posted December 30, 2020. The copyright holder for this preprint (which was not certified by peer review) is the author/funder, who has granted medRxiv a license to display the preprint in

It is made available under a CC-BY-NC-ND 4.0 International license .

The introduction of any electrical wire into the MRI magnet bore may result in undesired artifact and/or noise. Whereas the magnetic fields induced by the current in wires and electrodes during tDCS have been known to lead to false-positive activation in BOLD fMRI, tACS is far less prone to this artifact since the $A C$ induces relatively rapid polarity switching magnetic fields that time average to zero net effect (Antal et al., 2014a). However, any electrical cabling used in tES-MRI experiments may act as a transmitter of RF energy from outside the MRI shielded environment, and therefore may potentially increase electromagnetic RF interference with the MRI signal--even with the stimulator switched off. It is therefore extremely important to use an RF filtering method to suppress any external electromagnetic noise that may find its way into the scanner room using the stimulator's cabling as a tunnel. Currently, there are two hardware configurations for addressing this issue (Esmaeilpour et al., 2019): (1) The RF waveguide setup, which includes two filter boxes positioned outside and inside of the scanner room and cables running from the MRI control room through the RF waveguide tube (Meinzer et al., 2014; Williams et al., 2017); (2) The RF penetration panel setup, which includes an RF filter adapter connected directly to the RF penetration panel and MRI ground, positioned outside of the scanner room with cables running from the stimulator in the MRI control room through filter and RF penetration panel and to the electrode leads in the scanner room (Lefebvre et al., 2019).

It is therefore recommended unanimously by the contributors to report this information which was rated to be moderately important (item 1.7, average rating score: 3.50 ) as precisely as possible. Additionally, it is recommended that the authors provide details regarding the attenuation characteristic of RF filtering (recommendation 1.7.1, recommended by $50 \%$ of the contributors) (Antal et al., 2011; Vosskuhl et al., 2016). For instance, "in the case of concurrent tDCS-fMRI, the characteristic bandwidth of the stop band of the filters on the DC path have been chosen to provide an approximate attenuation of $60 \mathrm{~dB}$ within a frequency range of $20-200 \mathrm{MHz}$ to mitigate the radio frequency noise, protecting common strength MRI scanners such as $1.5 \mathrm{~T}$ and $3 \mathrm{~T}$ which operate at Larmor frequencies of approximately $64 \mathrm{MHz}$ and $128 \mathrm{MHz}$ during fMRI (proton imaging) (Antal et al., 2011)“.

The wire routing pattern is also an important methodological detail when using transcranial stimulation simultaneously with $\mathrm{fMRI}$ measurement to increase replicability and validity of a study. However, it was rated as being moderately important overall (item 1.8, average rating score: 3.43 ). It is important to make sure that the wires/cables do not create loops and run parallel to the bore axis as they approach and exit the scanner. It is also recommended by $58 \%$ of the contributors to ensure that after the subject enters the scanner, no loop can be created subsequently due to wire movements, and practical measures to avoid them should be stated explicitly (recommendation 1.8.1). An example is a protocol reported by Williams and colleagues in which they emphasize that regarding the stimulator setup, they ensured that no loop was made by the wire and it was placed along the wall of the room (Williams et al., 2017). It might be of importance (recommendation 1.8.2, recommended by $61 \%$ of the contributors) to include a figure illustrating the wiring details, such as the length of the cables required to connect inner and outer filter boxes, how the cables are connected to the electrodes, in which direction the cables are leaving the head, how multiple connecting cables are managed together, and depending on the geometry of the head coil, how the cables are entering the coil. Researchers are also encouraged (recommendation 1.8.3, recommended by $59 \%$ of the contributors) to report how they controlled the cable motion inside the scanner (e.g., via sandbag, tape, etc.). One reason for doing so is to make sure that no loop is created by movements (Meinzer et al., 2014). The contributors stress the importance to report if 
medRxiv preprint doi: https://doi.org/10.1101/2020.12.23.20248579; this version posted December 30, 2020. The copyright holder for this preprint (which was not certified by peer review) is the author/funder, who has granted medRxiv a license to display the preprint in

It is made available under a CC-BY-NC-ND 4.0 International license.

there were any deviations from the device manufacturers' recommendations due to study purposes (recommendation 1.8 .4 recommended by $78 \%$ of the contributors). There are different institutional policies in various countries regarding the use of electrical stimulators during MR imaging (e.g., permission to transfer electrical current through the penetration panel); However, only $29 \%$ of responders recommended to report limitations at the levels of institutions/countries based on regulations or policies (recommendation 1.8.5). This information might not be required as it does not affect the results of the study if the methods are transparent.

The full potential of simultaneous tES and $\mathrm{fMRI}$ acquisition, such as dynamic monitoring of the brain during tES, can only be explored if the data of both systems are temporally synchronized. As the analysis depends critically on properly timed stimulation, it is crucial to synchronize imaging and stimulation. It is therefore recommended by the contributors to report this information which was rated to be moderately important (item 1.9, average rating score: 3.70 ) as precisely as possible. In general, to address this issue, the presentation computer receives a volume trigger TTL output from the MRI scanner and also sends output TTL triggers to the stimulator at desired stimulation times through a stimulus presentation software (Violante et al., 2017). Additionally, as synchronization protocols vary from center to center, it is recommended to clearly specify which method was used when sending the trigger pulse (recommendation 1.9.1, recommended by $96 \%$ of the contributors). There are several methods for addressing this issue, e.g., (1) USB, (2) parallel port, or (3) other additional devices. Two devices most commonly used for sending the trigger pulse include a USB DAQ device, which works well for the Psychtoolbox software package (Kleiner et al., 2007), and a USB-to-Serial port device, which works well for the E-Prime software package (Schneider et al., 2002).

Table 2| Concurrent tES-fMRI (ContES 2021) Checklist: main items and recommendations of the TECHNOLOGICAL FACTORS category to report in concurrent tES-fMRI research. Ratings for items (scores 1-5) are reported as mean (standard deviation) and ratings for recommendations (Yes/No) are reported as frequency of Yes (percent of Yes reports).

\begin{tabular}{|c|c|c|c|c|}
\hline \multirow[t]{2}{*}{ Categories/Sub-Categories } & Main Items to Report & $\begin{array}{c}\text { Item } \\
\text { Importance } \\
(1 \text { to } 5) \\
\end{array}$ & Specific Recommendation & $\begin{array}{l}\text { Recommendation } \\
\text { Inclusion } \\
\text { (Yes/No) }\end{array}$ \\
\hline & & Mean (SD) & & Yes (\%) \\
\hline \multicolumn{5}{|l|}{ TECHNOLOGICAL FACTORS } \\
\hline $\begin{array}{l}\text { 1.1. Manufacturer of MR } \\
\text { Conditional Stimulator }\end{array}$ & $\begin{array}{l}\text { The brand and model (if a brand } \\
\text { is providing different MR } \\
\text { conditional models) for the MR } \\
\text { conditional stimulator. }\end{array}$ & $4.37(0.96)$ & & \\
\hline $\begin{array}{l}\text { 1.2. MR Conditional Electrode } \\
\text { Details }\end{array}$ & $\begin{array}{l}\text { The MR conditional electrode } \\
\text { type (i.e., conductive polymer } \\
\text { with or without a sponge or } \\
\text { other conductive medium } \\
\text { holders). }\end{array}$ & $4.06(1.01)$ & $\begin{array}{l}\text { 1.2.1. Report conductive properties of the MR } \\
\text { conditional electrodes, cables, contact medium, } \\
\text { and other conductive elements, including the } \\
\text { position and materials used for the electrode- } \\
\text { cable connections (Saturnino et al., 2015). This } \\
\text { is especially important if they are not from an } \\
\text { established manufacturer or not well described } \\
\text { in the prior literature. However, even for well- } \\
\text { established equipment, these details are critical } \\
\text { to report to ensure replicability. }\end{array}$ & $44(85 \%)$ \\
\hline 1.3. Electrode Positioning & $\begin{array}{l}\text { The method for electrode } \\
\text { placement over the head inside } \\
\text { the scanner (i.e., targeting } \\
\text { software, } 10-20 \text { convention } \\
\text { with or without EEG cap, }\end{array}$ & $4.83(0.60)$ & $\begin{array}{l}\text { 1.3.1. Report electrode positioning as precisely } \\
\text { as possible to facilitate reproduction. It is } \\
\text { usually inadequate to simply report an } \\
\text { anatomical target, for example, "the anodal } \\
\text { electrode was placed over M1". }\end{array}$ & $51(100 \%)$ \\
\hline
\end{tabular}


medRxiv preprint doi: https://doi.org/10.1101/2020.12.23.20248579; this version posted December 30, 2020. The copyright holder for this preprint (which was not certified by peer review) is the author/funder, who has granted medRxiv a license to display the preprint in

It is made available under a CC-BY-NC-ND 4.0 International license .

functional targeting (fMRI), computational head models or others).

1.3.2. Report whether electrode positioning is based on the individual anatomy or a group template if imaging or head modeling is used for electrode positioning.

1.3.3. Report how electrode positioning is performed at the individual participant level. For example, was a neuronavigation system used or the EEG 10-20 system or something else.

1.3.4. Report the methods to ensure that the same electrode locations were used again if there are multiple sessions.

1.3.5. Report clearly how the electrodes are held in place inside the scanner including use of head-gear or customized supports.

1.3.6. Report how electrodes and their connecting cables over the head are located in relationship to the MR head coil while the subject is laying down inside the scanner and how the head was held in place - e.g., pillows, foam, etc. to ensure that position of head/electrodes remain in the same place during the scans while the convenience of the participant is ensured.

1.3.7. Report a post-hoc validation of the electrode positioning based on anatomical images with the electrodes in place if practical. For optimal validation, current density models based on anatomical images may be used (e.g., ROAST, SIMNIBS, etc.). It would be even better to directly measure the electric fields using magnetic resonance current density imaging (MRCDI) and MR electrical impedance tomography (MREIT) (Göksu et al., 2018), however, MREIT and MRCDI are still not available in most of the institutes.

1.4.1. Report a photo or a schematic figure or technical details showing in a reproducible way how the electrode with the MR conditional skin-electrode interface is connected to the cranium (including a view from the underneath

The MR conditional skinelectrode interface (saline solution, conductive paste, gel, etc.).
1.4. MR Conditional SkinElectrode Interface

\subsection{Amount of Contact Medium (Paste/Gel/Electrolyte)}

The amount or thickness of medium that is used for each electrode or a method to control this confounding variable.
$4.09(0.90)$ of the electrode if needed). If headgear or headstraps obscure the electrodes, you may provide an image without the headstraps.

1.4.2. Report any other MR-specific strategies to restrict the contact medium (such as within an electrode holder) to avoid short circuits.

1.5.1. Report technical details/difficulties in measuring the thickness of the layer of conductive material underneath the electrodes and how cream/gel underneath the electrodes is evenly distributed. Although this can be important, mainly when having big electrodes, in practice, the amount of cream/gel 2.91 (1.13) underneath the electrodes may not be evenly distributed. Developing new methods to measure, control, and report this important variable are desired. Reporting the impedance (before, during, and after stimulation) provides insight on electrode contact quality, but is not in itself a substitute for controlling and 
medRxiv preprint doi: https://doi.org/10.1101/2020.12.23.20248579; this version posted December 30, 2020. The copyright holder for this preprint (which was not certified by peer review) is the author/funder, who has granted medRxiv a license to display the preprint in It is made available under a CC-BY-NC-ND 4.0 International license .

\subsection{Electrode Placement Visualization}

Any photo/diagram/figure to precisely visualize the electrode montage inside the scanner and make replication possible.

$3.56(1.17)$

1.7.1. Report the attenuation characteristic of the RF filtering.

$25(50 \%)$

(stimulator device connected to the subject via penetration panel (e.g., RF filters from different brands) or connected via waveguide with $\mathrm{RF}$ boxes on

$3.50(1.07)$ 1.7.2. Report any potential regulatory consideration/limitation at the institute/university/country level. either end).

Wire routing pattern (out back of bore and around the control room or straight down front of bore to control room).

1.8.1. Report whether/how the state of the

1.8. Wire Routing Pattern

1.9. tES-fMRI Machine Synchronization/Communication

\section{The}

synchronization/communication method between the $\mathrm{tES}$ device, the stimulus delivery PC, and the scanner. cables is checked after the subject entering the scanner to avoid creating any loops.

1.8.2. Report the length of the cables required to connect inner with outer box using box cable, how the cables are connected to the electrodes, in which direction the cables are leaving the head, how multiple connecting cables are managed together, and depending

$3.43(1.22)$ on the geometry of the head coil, how the cables are entered into the coil. A sketch might be helpful to visualize these details.

1.8.3 Report how the cables and filter boxes are secured to prevent motion during the scan (i.e., sandbag, tape, etc.).

1.8.4. Report if there are any modifications from manufacturer recommendations.

1.8.5. Report any potential regulatory consideration/limitation at the institute/university/country level.

1.9.1. Report any synchronization between tES and MRI. Synchronization/communication can be TTL scanner sync pulse to trigger/sync (tES and/or non-tES) stimulus recorded via USB/parallel port/NI device; use of markers for $\mathrm{tES}$, or manual triggering of the TES device.

\subsection{Safety and Noise Tests}

Reporting technical parameters that can be safety-relevant was considered as highly important (item 2.1, average rating score: 4.37). Ensuring the safety of the equipment for all possible MR environments and applications is usually not possible. Rather, most equipment is demonstrated to be $M R$ conditional, i.e., safe under specific usage conditions in specific MR environments (Shellock et 
medRxiv preprint doi: https://doi.org/10.1101/2020.12.23.20248579; this version posted December 30, 2020. The copyright holder for this preprint (which was not certified by peer review) is the author/funder, who has granted medRxiv a license to display the preprint in It is made available under a CC-BY-NC-ND 4.0 International license.

al., 2009). This implies that the same equipment might still pose safety risks when used in untested scenarios, requiring a reevaluation of its safety.

Manufacturers of tES equipment should clearly document the safety-relevant technical parameters and settings used for their testing to ensure that users can replicate those appropriately. While it was less frequently recommended to repeat these parameters in the paper (recommendation 2.1.2, recommended by $51 \%$ of the contributors), deviations should be clearly reported, including the measures that were taken to ensure that safety was not compromised. To provide some guidance, the following paragraph gives a brief overview of aspects that can be safety-relevant and thus warrant consideration. Generally, external equipment brought inside the MR scanner might cause harmful effects via interaction with the static magnetic field, the magnetic gradient fields, and the transmitted radiofrequency (RF) field (Panych and Madore, 2018):

(1) The static magnetic field exerts strong accelerating forces on ferromagnetic materials. In the case of tES-fMRI, using only non-magnetic materials for the cables and electrodes is a straightforward way that should be taken by the equipment manufacturer to prevent safety risks.

(2) The time-varying magnetic gradient fields can create eddy currents in a conductive material that in turn result in mechanical forces via their interaction with the static field. This effect seems less relevant in the case of tES-fMRI for which the cables are the only high conductive parts. As they do not form closed high-conductive loops at the low electromagnetic frequencies corresponding to the time-varying gradient fields but are interrupted by the head, the electrodes, the stimulator, and often also safety resistors, the currents induced by gradient field switching are weak. This effect might, however, cause vibrations of the cables and might contribute to local nerve stimulation underneath the electrodes, while serious adverse effects such as burns due to tissue heating are unlikely (Panych and Madore, 2018).

(3) Interactions of cables and electrodes with the transmitted radiofrequency (RF) field can potentially lead to local tissue heating and burns, which has been described, e.g., for electrocardiogram equipment (Dempsey et al., 2001; Dempsey and Condon, 2001). The MR scanner controls the transmit power to ensure that the specific absorption rate (SAR), i.e., the mean power deposition per unit tissue weight, stays within safe limits everywhere in the body. When cables are brought into the scanner, they can absorb and redistribute RF energy. By that, they might heat up and additionally locally focus RF energy in close-by body tissue. Both mechanisms can cause burns. They can occur for wire loops, but also for more or less straight cables that act as antennas, depending on several parameters including wire length and path, the terminal conditions at the electrodes, the frequency of the RF transmit field (linearly scaling with the MR field strength as long as only hydrogen nuclei are imaged), the spatial extent of the RF transmit field and the head and body position inside the field. Some of these parameters are difficult to standardize in practice so it is worth noting that the absence of heating in a test scan might not necessarily generalize. The safety of cables can be relevantly improved by adding resistors or cable traps or using lower conductive carbon instead of copper wires to systematically reduce or fully prevent the occurrence of standing waves. While these measures can be very effective, expert knowledge is required when implementing them to ensure that they work as intended and in a wide range of practical scenarios (Kozlov et al., 2018). When space allows, a simple measure to reduce the risk of burns is to ensure a physical distance between the cables and the skin. However, this does not help to prevent burns around points of high resistance, e.g., at the connection to the electrode, which is generally more likely. 
medRxiv preprint doi: https://doi.org/10.1101/2020.12.23.20248579; this version posted December 30, 2020. The copyright holder for this preprint (which was not certified by peer review) is the author/funder, who has granted medRxiv a license to display the preprint in

It is made available under a CC-BY-NC-ND 4.0 International license.

The electrodes and gel are far less conductive than metal so that their interaction with the RF transmit field is relevantly smaller. However, as the rubber electrodes still have better ohmic conductance than body tissue (e.g., $\sim 30 \mathrm{~S} / \mathrm{m}$ for the silicon rubber), they can cause a redistribution of the electric field that is created by the RF transmit field inside the head (Kozlov et al., 2020). This effect can change the local SAR distribution and potentially cause local skin heating. Its strength depends on the size, shape, and position of the electrodes, with the tendency that heating will be stronger for larger and thicker rubber electrodes.

The strength and duty cycle of the RF transmit field depends on the MR sequence type, which translates to the amount of local SAR increases that might occur due to electrodes or cables. Standard gradient-echo EPI used for functional brain imaging has comparatively low SAR. The SAR of newer multiband EPI and in particular turbo spin echo sequences (RARE, TSE, FSE, FLAIR, T2-SPACE, ...) for T2-weighted structural imaging can be close to the allowed limits and might exceed it locally when cables and electrodes are present.

To summarize, interactions of the tES cables and electrodes with the RF transmit field dependend on several parameters, which can make it difficult to generally ensure that local heating of the skin is kept within safe limits. Measures such as resistors added to the cables can reduce the risk of inducing adverse effects, but it remains important that the tES equipment is employed within the technical parameter ranges that are cleared by the manufacturer. These parameters include the MR field strength, the type of transmit coil (body coil vs birdcage coil or transmit array), the MR sequence type and settings, the cable paths, the electrode sizes as well as their shape, position, and material.

According to our knowledge, with the concurrent application of the methods, no higher number of reported adverse events (AEs) compared to conventional tES applications and no serious adverse events (SAEs) were reported (Antal et al., 2017). Nevertheless, the study protocol must always comply with the safety standards for both tES and MRI and these parameters should be carefully documented in the protocol/paper. More detailed suggestions and recommendations of experts can be found in Table 3.

Experiments should always start with safety testing when a new protocol is applied. These safety tests should include, but are not limited to, impedance testing, temperature testing (any temperature change under electrodes) (Moisa et al., 2016), and electric current tolerance testing (recommendation 2.2.1, recommended by $71 \%$ of the contributors). As suggested by at least 45 respondents (Figures 2 and 3), it is highly recommended to report impedance changes before and during the course of scanning and using a gel under the electrode (and not saline-soaked sponges) in order to avoid impedance increase (recommendation 2.5.1, recommended by $88 \%$ of the contributors).

The measurement of signal-to-noise ratio (SNR) was rated 3.91 (item 2.4), reflecting an important aspect in tES-fMRI studies. A small number of papers reported SNRs during the concurrent application of $\mathrm{tES}$ and $\mathrm{fMRI}$, although it is well-known that electrical equipment can compromise image SNR via several mechanisms resulting in distorted images and false-positive changes (Moisa et al., 2016). The stimulator is connected to the MR-compatible electrodes by specially designed leads. In some devices, the stimulating leads are passed through a waveguide tube in the MR cabin wall and through a radiofrequency filter module, consisting of two filter boxes. In other stimulators, there is only one filter attached to the patch (penetration) panel of the MRI (to ensure that the Faraday cage of the MRI room is not opened) and there is no noise induced during the normal MRI image acquisition. Nevertheless, a small amount of noise is frequently present. 
medRxiv preprint doi: https://doi.org/10.1101/2020.12.23.20248579; this version posted December 30, 2020. The copyright holder for this preprint (which was not certified by peer review) is the author/funder, who has granted medRxiv a license to display the preprint in

It is made available under a CC-BY-NC-ND 4.0 International license.

At least two papers reported susceptibility artifacts underneath the electrodes restricted to the skull layer with no visual evidence of any distortion in brain EPI images (Antal et al., 2011; Gbadeyan et al., 2016). Another study using $\mathrm{fMRI}$ measurements during tES in cadavers observed significant BOLD signal changes (Antal et al., 2014a). Therefore, careful inspection of the SNR in different conditions during data acquisition is of critical importance to diminish errors and issues related to false-positive results. However, sometimes it is very difficult to deal with tES-fMRI artifacts because they might emerge sporadically, can be stimulation protocol and montage specific (e.g., tDCS seems to induce more noise than tACS) and often are not reproducible. Artifacts can be caused by many factors, by the noise of the stimulator itself, by the electrode/cable positions relative to the direction of the magnetic field, or by individual anatomical differences. Artifact removal is not trivial and may depend on the applied task in the scanner and processing methods. Beyond manual inspection, in a recent study, independent component analysis (ICA) was used to automatically remove noise in concurrent tDCS-fMRI (Li et al., 2019b). Manual inspection suggested that by applying this method, noise was successfully removed from the voxel's time series.

As suggested in Table 3, our recommendations are: (1) tES manufacturers should state in the manual to what degree SNR changes during stimulation. As SNR will depend on the local settings, the type of the scanner (e.g., its shimming performance), and the MR sequences, several tests are suggested at different locations. This scan can be achieved using phantoms and in human subjects targeting different ROls, tES-doses, and electrode positions (Antal et al., 2011). Basing the tests on the spherical agar phantom and the procedures outlined in the Function Biomedical Informatics Research Network (fBIRN) protocol would be a good starting point to ensure that the results of the quality tests are comparable between different MR sites and tES equipment (Friedman and Glover, 2006). They should be complemented by measurements of the RF noise spectrum using the standard test sequences provided by scanner manufacturers, and by field mapping sequences to quantify the distortion of the static magnetic field by tES equipment (Moisa et al., 2009). (2) When a new stimulator or protocol is tested, pilot in-scanner investigations, first using phantoms and later healthy human participants, are necessary and any incident or the absence of incidents should be reported. (3) SNR testing should always be done before the study starts (pilot measurements). (4) Later, during the study phase, when artifacts/SNR changes occur, it should be reported how many participants or runs were excluded from the analysis due to artifacts. Visualization of the artifacts is suggested. (5) If other devices are involved during the tES-fMRI session, it should be tested whether these devices or the interactions can modify SNR. In the protocol, it should be clearly stated how tES-induced noise can be or was separated from other types of noise.

Subjective tolerance was reported in only $33 \%$ of the concurrent tES-fMRI articles in our systematic review. A gradual intolerance/side effects (itching sensation, burning, pain) may be the source of non-tES induced BOLD changes. This is particularly important for online tES studies but may also have an impact on offline tES. Subjective intolerance that leads to study discontinuation should always be reported. In addition, it is recommended that gradual subjective intolerance is reported (recommendation 2.3.1, recommended by $98 \%$ of the contributors). The Comfort Rating Questionnaire (CRQ) offers a good way to do this (Palm et al., 2014). It measures sensations such as pain, tingling, burning, fatigue, nervousness, concentration, vision, sleep disturbances, headaches, and flashes of light before, during and after stimulation, wherever possible as a visual analogue scale between 1 (not at all) - 10 (extreme). Subjective intolerance reporting (item 2.3) was rated 4.33 by the contributors. This indicates consensus that it is important to report this item in the publication. 
medRxiv preprint doi: https://doi.org/10.1101/2020.12.23.20248579; this version posted December 30, 2020. The copyright holder for this preprint (which was not certified by peer review) is the author/funder, who has granted medRxiv a license to display the preprint in It is made available under a $\mathrm{CC}-\mathrm{BY}$ -

Table 3| Concurrent tES-fMRI (ContES 2021) Checklist: main items and recommendations of the SAFETY and NOISE TESTS category to report in concurrent tES-fMRI research. Ratings for items (scores 1-5) are reported as mean (standard deviation) and ratings for recommendations (Yes/No) are reported as frequency of Yes (percent of Yes reports).

\begin{tabular}{|c|c|c|c|}
\hline $\begin{array}{l}\text { Categories/Sub- } \\
\text { Categories }\end{array}$ & $\begin{array}{c}\text { Item } \\
\text { Importance } \\
\text { (1 to } 5) \\
\end{array}$ & Specific Recommendation to Report & $\begin{array}{c}\text { Recommendatio } \\
\text { Inclusion } \\
\text { (Yes/No) }\end{array}$ \\
\hline & Mean (SD) & & Yes (\%) \\
\hline
\end{tabular}

\section{SAFETY and NOISE TESTS}

\begin{tabular}{ll}
\hline & The technical \\
& specifications of the \\
& MR scanner, the \\
& applied fMRI \\
& sequences, and the \\
2.1. MR & used tES settings and \\
Conditionality & configuration to fall 4.37 (0.99 \\
Specifics for tES & within the specifics of \\
Setting & MR conditionality \\
& based on tES \\
& manufacturer \\
& guideline.
\end{tabular}

2.1.2. Report the details of MR conditionality that are demonstrated by the manufacturer of the tES equipment for specific conditions of use.

2.1.1. Report the technical specifications of the MR scanner, including field strength, RF transmit coil type, maximal transmit power, and the number of head coil channels. Standard guidelines for proper reporting on MRI/fMRI parameters should be considered (Grainger, 2014; Nichols et al., 2017; Poldrack et al., 2008).

\section{2. tES-fMRI}

Setting Test - Safety Testing
The safety of the tESfMRI setting.
$3.93(1.23)$
2.2.1. Report safety tests and respective details which include but are not limited to impedance testing, temperature testing (any temperature change under electrodes) and electric current tolerance testing, etc. with real human subjects or phantoms. Whenever the safety testing is referred to a previous study, it is still recommended to provide a brief description of the safety tests that have been considered.
$37(71 \%)$

2.2.2. Report the occurrence/absence of any safety incidents. $48(96 \%)$

\begin{tabular}{ll}
\hline 2.3. tES-fMRI & The number of cases \\
Setting Test - & that have not \\
Subjective & tolerated the \\
Intolerance & tES/fMRI session \\
Reporting & (even if it is zero).
\end{tabular}

The noise/artifact induced by the tES setting in the fMRI signal with real human subjects or phantoms before starting the study (It can be reported or referred to previous studies with the same setting).
2.3.1. Report the reasons that participants have not tolerated the 4.33 (0.92) tES/fMRI session if any (i.e., burning sensation, increased temperature, pain, shortness of breath, nausea, etc.).
2.4. tES-fMRI Setting Test Noise/Artifact
2.4.1. Report or cite prior analysis on the degree to which the equipment alone, and the equipment during stimulation affects the SNR. Importantly, such analysis is specific to the protocol (electrode preparation, imaging sequence) such that claims cannot be automatically generalized without analysis. For instance, $\sim 8 \%$ as described in (Antal et al., 2011) ("... SNR was hardly reduced with decreases ranging from 3 to $8 \%$ for the different ROls and setups, even in the gray matter ROI in M1 targeted by tDCS....").

3.91 (0.99) 2.4.2. Report how many participants, or runs were excluded from the analysis due to artifacts. Exclusion criteria should be reported as well (e.g., based on visual inspection or any data analysis tool that might $50(96 \%)$ detect artifacts for single runs).

2.4.3. Report the quantification of the possible increase in artifact or noise If the task-related $f M R I$ requires the use of some other devices, such as tactile/pain stimulators, olfactory or juice machines, etc. (e.g., compare the noise/artifacts of the tES-fMRI setup alone with the tESfMRI setup with the addition of the respective device). 
medRxiv preprint doi: https://doi.org/10.1101/2020.12.23.20248579; this version posted December 30, 2020. The copyright holder for this preprint (which was not certified by peer review) is the author/funder, who has granted medRxiv a license to display the preprint in It is made available under a CC-BY-NC-ND 4.0 International license .

2.4.4. Report baseline "pre-tES" fMRI as a part of the data acquisition sequence in the imaging session to investigate the effects/noise introduced by the tES setup per se (without any stimulation and within subject). Although this will not be sufficient to fully control for noise induced by $\mathrm{tES}$ administration with problems such as scanner drift, and the order effect.

2.4.5. Report any special fMRI processing measures or assessments that are used to deal with $\mathrm{tES}$-induced imaging artifacts if applicable.

Impedance monitoring (i.e., before entering the 2.5. Impedance Testing scanner room and/or in the scanner room and/or inside the scanner and/or during scanning).
2.5.1. Report the impedance (i.e., cut off criterion programmed in the device, or measures on an individual basis with mean/range across groups before, during, and after scanning).

$4.17(1.00)$

2.5.2. Report the methods applied to verify the current delivered inside the scanner (if any). Some devices already include an independent current meter and some investigators use their own external devices.
$45(88 \%)$

$42(82 \%)$

\subsection{Methodological Factors}

It is crucial for studies to be precise about the timing of tES application relative to $\mathrm{fMRI}$ acquisition and also relative to any behavioral task performed, for both technical and experimental reasons. The checklist contains two items related to this specific point, and it is the committee's position that the two items on the checklist relating to this point (Items 3.1 and 3.2) should be reported to a high level of detail (Table 4).

This is to address three issues in particular. First, tES-fMRI studies targeting sensorimotor cortex have clearly shown that the acute stimulation effects during tDCS are not the same as its poststimulation effects (Sehm et al., 2013, 2012). Therefore, knowledge about fMRI effects during stimulation cannot be simply extrapolated. Second, it is also increasingly recognized that brain state is an important determinant of the BOLD response to tES (Li et al., 2019b; Violante et al., 2017). This is not surprising, given that tES is thought to modulate spontaneous neuronal activity via subthreshold changes of membrane polarization without directly eliciting action potentials. Thus, it is vital that studies report exactly when stimulation was applied during the task, so that findings can be interpreted with knowledge of the underlying brain state. One final issue is that there is still relatively little known about the duration and nature of after-effects of tES. Early tDCS studies used the classical bipolar montage to stimulate the motor hand area and measured the motor-evoked potential (MEP), rather than $\mathrm{fMRI}$, as the physiological outcome. These seminal studies suggest that at least three minutes of continuous stimulation are needed to produce after effects on corticomotor excitability (Nitsche and Paulus, 2000) and that prolongation of stimulation within specific windows can prolong after-effects (Nitsche et al., 2003; Nitsche and Paulus, 2001). But these dose-response relationships have been less frequently studied for other brain areas (Antal et al., 2004; Matsunaga et al., 2004) and have yielded somewhat divergent results. This also applies to the concurrent tES-fMRI approach (Jamil et al., 2020).

We recommend that the timeline of experimentation is reported in detail together with other design related information, such as counterbalancing of scans for within-subject studies, and whether subjects are repositioned in between scan runs should also be reported. This level of detail helps the reader to evaluate the results in the appropriate context and will enable the replication of techniques by other researchers.

For concurrent $\mathrm{tES} / \mathrm{fMRI}$ studies, besides the importance of reporting the timing of $\mathrm{tES}$ relative to the timing of $\mathrm{fMRI}$, it is also important to report the precise timing of tES within a particular $\mathrm{fMRI}$ 
medRxiv preprint doi: https://doi.org/10.1101/2020.12.23.20248579; this version posted December 30, 2020. The copyright holder for this preprint (which was not certified by peer review) is the author/funder, who has granted medRxiv a license to display the preprint in

It is made available under a CC-BY-NC-ND 4.0 International license .

imaging sequence (item 3.2, average rating score: 4.09). This is critical in order to assess the temporal relationship between tES and physiological activity acquired from fMRI, particularly in scenarios where the stimulation itself is dynamic (e.g., tACS, or during the ramping up/down of tDCS), which may then lead to different dynamics in fMRI-recorded physiological activity. For example, in a tDCS-fNIRS (functional near-infrared spectroscopy) study on a small sample of stroke patients, anodal tDCS resulted in non-stationary changes in blood oxygenation at the start of stimulation, possibly due to stimulation-induced changes in blood vessel dilation or neurovascular coupling (Durand et al., 2002; Dutta et al., 2015). This issue deserves additional consideration in block designs where stimulation is applied in an on-off-on sequence. Here, physiological effects obtained by fMRI could possibly further be confounded by carryover or homeostatic effects due to repeated stimulation (Fricke et al., 2011; Monte-Silva et al., 2013). Researchers interested in employing such a block design or repeated-stimulation approach may want to consider assessing the temporal stability of their stimulation protocol on their fMRI signal of interest. In all cases, the experts advise that care should be taken to report the precise stimulation start time in relation to the start of the imaging sequence, and a diagram or schematic be included along with the methodological description in order to provide maximum clarity to the readers.

Reporting tES-associated sensations is crucial when using tES in any experimental or clinical setting, both for safety and methodological reasons. This item was rated with 4.06 which shows a high agreement within the panel regarding its relevance when reporting the methods in tES-fMRI studies. Different stimulation protocols can induce different sensory experiences and associated brain activity changes, which can in principle be confounded with true direct tES effects. Experimenters should consider this as a possible confound, e.g., when comparing between stimulation protocols and/or montages. For example, in the case of tACS, cutaneous sensation and phosphene perception are frequency-specific (Turi et al., 2013) and also differ between brain states (e.g., lightning conditions, eyes-open vs eyes-closed (Cabral-Calderin et al., 2016; Kanai et al., 2008)). Moreover, phosphene intensities have been shown to correlate with tACS-induced BOLD signal changes in the insular cortex, during $10 \mathrm{~Hz}$ stimulation (Cabral-Calderin et al., 2016). In addition to phosphenes, or cutaneous sensations, different tES montages can potentially induce different levels of discomfort, especially while participants are lying in the MRI (e.g., depending on the proximity between the electrodes and the RF coil and also on electrode location (e.g., if located on the back of the head)). When interpreting tES effects, it is important to carefully evaluate associated experiences to separate secondary from direct tES effects.

Reporting tES-associated sensory experiences is also crucial for safety reasons (see also section 4.2, subjective intolerance item). Asking participants to report on several factors such as electric current tolerance, headache, nausea, burning sensation, and pain can help experimenters to better monitor unwanted tES side effects, which will help to guarantee the safety of concurrent tES-fMRI protocols. Therefore, we recommend to assess and report tES-associated experiences before, during, and/or after tES (as appropriate). As stated in Table 4, we specifically recommend that: (1) tES associated sensory experience (e.g., tactile sensation, phosphene perception, burning sensation, and others) should be reported using rating scales or questionnaires (e.g., (Misselhorn et al., 2019; Palm et al., 2014)); additionally, participants should report whether they can differentiate between active and sham stimulation conditions (to assess the effectiveness of blinding whenever appropriate). The latter could be done by asking the participants to assign conditions in a forced choice manner. This would allow testing whether they perform above chance level in detecting real stimulation, even when consciously not being able to state a difference. (2) Electric current tolerance should be 
medRxiv preprint doi: https://doi.org/10.1101/2020.12.23.20248579; this version posted December 30, 2020. The copyright holder for this preprint (which was not certified by peer review) is the author/funder, who has granted medRxiv a license to display the preprint in It is made available under a CC-BY-NC-ND 4.0 International license .

reported before entering the scanner room (if technically possible), inside the scanner, and/or before/during scanning (as appropriate). (3) Experimenters should report any instructions or additional training/tests that were conducted before the tES-fMRI session to make the experiment more suitable for the participant.

Table 4| Concurrent tES-fMRI (ContES 2021) Checklist: main items and recommendations of the METHODOLOGICAL FACTORS category to report in concurrent tES-fMRI research. Ratings for items (scores 1-5) are reported as mean (standard deviation) and ratings for recommendations (Yes/No) are reported as frequency of Yes (percent of Yes reports).

\begin{tabular}{lccc}
\hline Categories/Sub-Categories & Main Items to Report & $\begin{array}{c}\text { Item } \\
\text { Importance } \\
\text { (1 to 5) }\end{array}$ & $\begin{array}{c}\text { Specommendation } \\
\text { Inclusion } \\
\text { (Yes/No) }\end{array}$ \\
\hline & Mean (SD) & Yes (\%) \\
\hline
\end{tabular}

\section{METHODOLOGICAL FACTORS}

3.1. Concurrent tES-fMRI Timing
The timing of concurrent tES within the FMRI paradigm.

3.1.1. Providing schematic diagrams is strongly encouraged to achieve maximum clarity for the reader.

$4.52(0.81)$

3.1.2. Report carry-over effects between different stimulation conditions and different brain states. How such effects have been considered or mitigated should be discussed.

3.2.1. Report the exact timing of all imaging events (structural or functional) before and after concurrent tES-fMRI.

$47(92 \%)$

3.2.2. Report when the tES setup is placed on the participant e.g., if the tES setup was placed on the participant at the start of the tES-fMRI session (and

The imaging events before and after concurrent tES-fMRI and respective sequences. was therefore on the participant during other non-

\subsection{Imaging Session Timing}

\section{3. tES Experience Report}

The assessment of the subjective experience of receiving $\mathrm{tES}$ inside the scanner.
$4.09(0.99)$ fMRI sequences).

3.2.3. In tACS studies, report how stimulation frequency is matched with TR. To reduce potential sources of biases in tACS-fMRI studies, the stimulation frequency should be set such that a full number of cycles fits into the TR of the functional measurement (Antal et al., 2014a) (post-mortem study). Otherwise, the tissue polarization might be averaged over the time of one volume measured.

3.3.1. Report the general experience (comfort/fatigue) and participant's other experiences with the stimulation - as some tES montages/protocols might be more uncomfortable/perceptible than others when lying inside the scanner and this could be a confounder when comparing across stimulation montages. Options include: assessing participant ratings of symptoms for each condition, asking participants whether they perceived stimulation or not for each condition, reporting on the presence and intensity of phosphenes/tactile sensation (in the case of tACS), etc. This is important as it could show whether participants can differentiate between stimulation conditions (e.g.) between active and sham stimulation, or between different frequencies (in the case of tACS). Having different side effects between sessions does not necessarily mean that subjects can discern and are unblinded.

3.3.2. Report electric current tolerance for subject comfort (i.e., before entering scanner room (if technically possible) and/or in the scanner room and 
medRxiv preprint doi: https://doi.org/10.1101/2020.12.23.20248579; this version posted December 30, 2020. The copyright holder for this preprint (which was not certified by peer review) is the author/funder, who has granted medRxiv a license to display the preprint in

It is made available under a CC-BY-NC-ND 4.0 International license .

inside the scanner and/or during scanning (as appropriate)).

3.3.3. Report any instructions, training, or exposure provided before the tES-fMRI session to make the experiment more convenient for the participants.

3.3.4. Report the exact wording or provide citations of the questions or questionnaires used to report on the subjective experience of receiving tES inside the scanner in the article or its supplements.

0.0.1. Report handedness of subject as a potential source of variability of tES-fMRI studies. This interaction could be addressed in relevant contexts either by limiting the sample to right-handed individuals, reporting handedness with quantitative standard instruments, or through methodological/analytical approaches which should

0.0.2. If possible, present the online tES electrodes as additional bumps in the surface/mesh reconstruction. This is a good possibility to determine the exact location of the online electrodes. However, this non-biological reconstruction may also influence simulations, so performance of additional structural $\mathrm{T} 1 \mathrm{w}$ and T2 $\mathrm{w}$ scans without the electrodes whenever possible is advantageous.

\subsection{Conclusion}

The ContES checklist for reporting the experimental procedures aims to promote best practices in concurrent tES-fMRI studies by encouraging open and detailed reporting of methods. We hope that by being compelled to report the items on the checklist, researchers will be encouraged to think more deeply about the scientific reasoning behind each choice. This will improve the technical and scientific standard of tES-fMRI studies, and also help to increase the reproducibility of results. This checklist could also be useful for the design of concurrent tES-fMRI studies. Addressing the checklist in pre-registered protocols will enhance the scientific rigor and replicability of protocols. As technological and methodological aspects of concurrent tES-fMRI studies advance over time, the steering committee of the checklist will work on future versions of the checklist to keep its details updated. To ensure the feasibility of the checklist application, we suggest considering the "items" (Supplementary Table 1) as a "routine" in concurrent tES-fMRI studies and "additional recommendations" as "suggestions" to improve the methodological design and report of concurrent tES-fMRI studies (Supplementary Table 3). As with any checklist, ultimately what items are important to document (and what items may not be relevant) will be study specific, and it is the responsibility of the investigator (with support from regulatory bodies and companies) to adapt appropriate standards. It is also not possible to anticipate any possible experiment set-up, equipment, or subject inclusion; where these factors all together govern risk-benefit determinations. Nonetheless, the development of generalized checklists provides standards and reference to leverage. And to the extent a comparable checklist is reported across efforts, reproducibility is made more transparent. All tES-fMRI studies should have standard operating procedures that include a checklist applied in setting up new protocols and/or prior to testing each subject. Finally, the success of this checklist should be assessed based on the adherence of authors, reviewers, and editors to its application in the reporting, editing, and peer-review process in the future. 
medRxiv preprint doi: https://doi.org/10.1101/2020.12.23.20248579; this version posted December 30, 2020. The copyright holder for this preprint (which was not certified by peer review) is the author/funder, who has granted medRxiv a license to display the preprint in

It is made available under a CC-BY-NC-ND 4.0 International license.

\section{Funding Supports}

Rany Abend is partially supported by the National Institute of Mental Health Intramural Research Program. Jorge Almeida is supported by an ERC Starting Grant (Grant\# 802553 - "ContentMAP"), and by grant PTDC/PSI-GER/30745/2017 from Fundação para a Ciência e a Tecnologia Portugal, and Programa COMPETE. Andrea Antal is supported by the Ministry for Science and Culture of Lower Saxony Germany (76251-12-7/19 ZN 3456). Daria Antonenko is supported by the Deutsche Forschungsgemeinschaft (DFG, German Research Foundation (AN 1103/3-1). Chris Baeken is supported by SRP57 and by Prevend 2.0. Helen Barron is supported by the Medical Research Council (MRC) UK (MC_UU_00003/4). Til Ole Bergmann is supported by the Boehringer Ingelheim Foundation and the Deutsche Forschungsgemeinschaft (DFG, German Research Foundation, Grant 362546008). Marom Bikson is supported by grants from the National Institutes of Health: R01NS101362, R01NS095123, R01NS112996, R01MH111896, R01MH109289. Matt Davis is supported by the UK Medical Research Council (SUAG044/G101400). Hamed Ekhtiari is supported by the Laureate Institute for Brain Research (LIBR), Warren K. Family Foundation, Oklahoma Center for Advancement of Science and Technologies (OCAST, \#HR18-139) and Brain and Behavior Foundation (NARSAD Young Investigator Award \#27305). Valentina Fiori is supported by the Italian Ministry of Health (grant GR-2018-12365991). Iman Ghodratitoostani is supported (Grant number: 2013/073750) by Innovation and Diffusion of Mathematical Sciences Center Applied to Industry (CEPID-CeMEAI) of Sao Paulo Research Foundation (FAPESP), the University of Sao Paulo. Gadi Gilam is supported by the Redlich Pain Research Endowment and the Feldman Family Foundation Pain Research Fund. Gesa Hartwigsen is supported by the Max Planck Society and by the German Research Foundation (HA 6314/3-1, HA 6314/4-1 and HA 6314/9-1). Tobias Hauser is supported by a Sir Henry Dale Fellowship (211155/Z/18/Z) from Wellcome \& Royal Society, an ERC Starting Grant, a grant from the Jacobs Foundation (2017-1261-04), the Medical Research Foundation, and a 2018 NARSAD Young Investigator grant (27023) from the Brain \& Behavior Research Foundation. Christoph Herrmann is supported by the German Federal Ministry of Education and Research (BMBF, grant nrs. 16SV7787 and 13GW0273D) as well as the German Research Foundation under Germany's Excellence Strategy (DFG, grant nr. EXC 2177/1 - Project ID 390895286). Chi-Hung Juan is supported by the Ministry of Science and Technology, Taiwan (grant no.108-2639-H-008-001-ASP; 108-2321-B-075 -004 -MY2) and sponsored by Taiwan Ministry of Education's “Academic Strategic Alliance: Taiwan and Oxford University" project grant. Daniel Keeser is supported by the German Center for Brain Stimulation (GCBS) research consortium (Work Package 5, Grant no. 01EE1403E), funded by the Federal Ministry of Education and Research (BMBF). Bart Krekelberg is supported by the National Institute of Neurological Disorders and Stroke and the National Institute of Mental Health under awards R01MH077711 and R21MH113917. Lucia M. Li is supported by an NIHR Clinical Lectureship, Academy of Medical Sciences Starter Grant and the NIHR Brain Injury MedTech Cooperative. SookLei Liew is supported by the National Institutes of Health (K01 HD091283, R01 NS11584). Timothy J. Meeker is supported by a Postdoctoral Scholarship from the Neurosurgery Pain Research Institute at the Johns Hopkins Medical Institute and National Institutes of Health (R01 NS107602). Marcus Meinzer is supported by the German Research Foundation (DFG ME 3161/3-1). Michael A. Nitsche is supported by Deutsche Forschungsgemeinschaft (DFG) - Projektnummer 316803389 - SFB 1280 "Funded by the Deutsche Forschungsgemeinschaft (DFG, German Research Foundation) Projektnummer 316803389 - SFB 1280, and the German Federal Ministry of Education and Research (BMBF, GCBS grant 01EE1501). Alexander Opitz is supported by RF1MH117428 and RF1MH124909. Christian Ruff is supported by an ERC Consolidator grant (BRAINCODES, Grant \#725355) and by the 
medRxiv preprint doi: https://doi.org/10.1101/2020.12.23.20248579; this version posted December 30, 2020. The copyright holder for this preprint (which was not certified by peer review) is the author/funder, who has granted medRxiv a license to display the preprint in It is made available under a CC-BY-NC-ND 4.0 International license.

Swiss National Science Foundation (Grant \# 100019L_173248). A. Duke Shereen is supported by National Institute of Neurological Disorders and Stroke under award R21NS115018. Hartwig R. Siebner holds a 5-year professorship in precision medicine at the Faculty of Health Sciences and Medicine, University of Copenhagen which is sponsored by the Lundbeck Foundation (Grant Nr. R186-2015-2138). Benjamin Thompson is supported by ClHR grant 390283, CFI grant 34095 and NSERC grants RPIN-05394 and RGPAS-477166. Axel Thielscher was supported by the Lundbeck foundation (R244-2017-196 and R313-2019-622). Dagmar Timmann is supported by the Deutsche Forschungsgemeinschaft (DFG, German Research Foundation) - Projektnummer 316803389 - SFB 1280. Ines Violante is supported by the BBSRC (BB/S008314/1). Benedikt Zoefel is supported by the European Union's Horizon 2020 research and innovation programme under the Marie SklodowskaCurie grant agreement number 743482. The views presented in this manuscript represent those of the authors and not necessarily those of the funding agencies.

\section{Declaration of competing interest}

The City University of New York holds patents on brain stimulation with Marom Bikson as inventor. Marom Bikson has equity in Soterix Medical Inc. Marom Bikson consults, received grants, assigned inventions, and/or serves on the SAB of Boston Scientific, GlaxoSmithKline, Mecta, Halo Neuroscience, X. Christoph Herrmann holds a patent for transcranial electric stimulation. Michael A. Nitsche is on the Scientific Advisory Boards of Neuroelectrics, and Neurodevice. Hartwig R. Siebner has received honoraria as speaker from Sanofi Genzyme, Denmark and Novartis, Denmark, as consultant from Sanofi Genzyme, Denmark and Lundbeck AS, Denmark, and as editor-in-chief (Neuroimage Clinical) and senior editor (Neurolmage) from Elsevier Publishers, Amsterdam, The Netherlands. He has received royalties as book editor from Springer Publishers, Stuttgart, Germany and from Gyldendal Publishers, Copenhagen, Denmark.

\section{References}

Abend, R., Sar-El, R., Gonen, T., Jalon, I., Vaisvaser, S., Bar-Haim, Y., Hendler, T., 2018. Modulating Emotional Experience Using Electrical Stimulation of the Medial-Prefrontal Cortex: A Preliminary tDCS-fMRI Study. Neuromodulation. https://doi.org/10.1111/ner.12787

Almeida, J., Martins, A.R., Bergström, F., Amaral, L., Freixo, A., Ganho-Ávila, A., Kristensen, S., Lee, D., Nogueira, J., Ruttorf, M., 2017. Polarity-specific transcranial direct current stimulation effects on object-selective neural responses in the inferior parietal lobe. Cortex 94, 176-181.

Antal, A., Alekseichuk, I., Bikson, M., Brockmöller, J., Brunoni, A.R., Chen, R., Cohen, L.G., Dowthwaite, G., Ellrich, J., Flöel, A., Fregni, F., George, M.S., Hamilton, R., Haueisen, J., Herrmann, C.S., Hummel, F.C., Lefaucheur, J.P., Liebetanz, D., Loo, C.K., McCaig, C.D., Miniussi, C., Miranda, P.C., Moliadze, V., Nitsche, M.A., Nowak, R., Padberg, F., Pascual-Leone, A., Poppendieck, W., Priori, A., Rossi, S., Rossini, P.M., Rothwell, J., Rueger, M.A., Ruffini, G., Schellhorn, K., Siebner, H.R., Ugawa, Y., Wexler, A., Ziemann, U., Hallett, M., Paulus, W., 2017. Low intensity transcranial electric stimulation: Safety, ethical, legal regulatory and application guidelines. Clin. Neurophysiol. 128, 1774-1809. https://doi.org/10.1016/j.clinph.2017.06.001

Antal, A., Bikson, M., Datta, A., Lafon, B., Dechent, P., Parra, L.C., Paulus, W., 2014a. Imaging artifacts induced by electrical stimulation during conventional fMRI of the brain. Neuroimage 85, 1040 1047. https://doi.org/10.1016/j.neuroimage.2012.10.026

Antal, A., Fischer, T., Saiote, C., Miller, R., Chaieb, L., Wang, D.J.J., Plessow, F., Paulus, W., 
medRxiv preprint doi: https://doi.org/10.1101/2020.12.23.20248579; this version posted December 30, 2020. The copyright holder for this preprint (which was not certified by peer review) is the author/funder, who has granted medRxiv a license to display the preprint in It is made available under a CC-BY-NC-ND 4.0 International license.

Kirschbaum, C., 2014b. Transcranial electrical stimulation modifies the neuronal response to psychosocial stress exposure. Hum. Brain Mapp. 35, 3750-3759.

Antal, A., Kincses, T.Z., Nitsche, M.A., Bartfai, O., Paulus, W., 2004. Excitability Changes Induced in the Human Primary Visual Cortex by Transcranial Direct Current Stimulation: Direct Electrophysiological Evidence. Investig. Ophthalmol. Vis. Sci. 45, 702-707. https://doi.org/10.1167/iovs.03-0688

Antal, A., Polania, R., Schmidt-Samoa, C., Dechent, P., Paulus, W., 2011. Transcranial direct current stimulation over the primary motor cortex during fMRI. Neuroimage 55, 590-596. https://doi.org/10.1016/j.neuroimage.2010.11.085

Ashizuka, A., Mima, T., Sawamoto, N., Aso, T., Oishi, N., Sugihara, G., Kawada, R., Takahashi, H., Murai, T., Fukuyama, H., 2015. Functional relevance of the precuneus in verbal politeness. Neurosci. Res. 91, 48-56. https://doi.org/10.1016/j.neures.2014.10.009

Bachinger, M., Zerbi, V., Moisa, M., Polania, R., Liu, Q., Mantini, D., Ruff, C., Wenderoth, N., 2017. Concurrent tACS-fMRI Reveals Causal Influence of Power Synchronized Neural Activity on Resting State fMRI Connectivity. J. Neurosci. 37, 4766-4777. https://doi.org/10.1523/JNEUROSCI.1756-16.2017

Bachtiar, V., Near, J., Johansen-Berg, H., Stagg, C.J., 2015. Modulation of GABA and resting state functional connectivity by transcranial direct current stimulation. Elife 4, e08789.

Baker, J.M., Rorden, C., Fridriksson, J., 2010. Using transcranial direct-current stimulation to treat stroke patients with aphasia. Stroke 41, 1229-1236.

Baker, M., 2017. Fostering reproducible fMRI research. Nat. Neurosci. https://doi.org/10.1038/nn.4521

Baker, M., 2016. Reproducibility crisis. nature.com. https://doi.org/10.1126/science.aac4716

Barron, H.C., Vogels, T.P., Emir, U.E., Makin, T.R., O'Shea, J., Clare, S., Jbabdi, S., Dolan, R.J., Behrens, T.E.J., 2016. Unmasking Latent Inhibitory Connections in Human Cortex to Reveal Dormant Cortical Memories. Neuron 90, 191-203. https://doi.org/10.1016/j.neuron.2016.02.031

Bikson, M., Rahman, A., 2013. Origins of specificity during tDCS: anatomical, activity-selective, and input-bias mechanisms. Front. Hum. Neurosci. 7, 688. https://doi.org/10.3389/fnhum.2013.00688

Buch, E.R., Santarnecchi, E., Antal, A., Born, J., Celnik, P.A., Classen, J., Gerloff, C., Hallett, M., Hummel, F.C., Nitsche, M.A., Pascual-Leone, A., Paulus, W.J., Reis, J., Robertson, E.M., Rothwell, J.C., Sandrini, M., Schambra, H.M., Wassermann, E.M., Ziemann, U., Cohen, L.G., 2017. Effects of tDCS on motor learning and memory formation: A consensus and critical position paper. Clin. Neurophysiol. https://doi.org/10.1016/j.clinph.2017.01.004

Cabral-Calderin, Y., Weinrich, C.A., Schmidt-Samoa, C., Poland, E., Dechent, P., Bahr, M., Wilke, M., 2016. Transcranial alternating current stimulation affects the BOLD signal in a frequency and task-dependent manner. Hum. Brain Mapp. 37, 94-121. https://doi.org/10.1002/hbm.23016

Chipchase, L., Schabrun, S., Cohen, L., Hodges, P., Ridding, M., Rothwell, J., Taylor, J., Ziemann, U., 2012. A checklist for assessing the methodological quality of studies using transcranial magnetic stimulation to study the motor system: An international consensus study. Clin. Neurophysiol. https://doi.org/10.1016/j.clinph.2012.05.003

Clark, V.P., Coffman, B.A., Mayer, A.R., Weisend, M.P., Lane, T.D.R., Calhoun, V.D., Raybourn, E.M., Garcia, C.M., Wassermann, E.M., 2012. TDCS guided using fMRI significantly accelerates learning to identify concealed objects. Neuroimage 59, 117-128.

Dempsey, M.F., Condon, B., 2001. Thermal injuries associated with MRI. Clin. Radiol. 
medRxiv preprint doi: https://doi.org/10.1101/2020.12.23.20248579; this version posted December 30, 2020. The copyright holder for this preprint (which was not certified by peer review) is the author/funder, who has granted medRxiv a license to display the preprint in It is made available under a CC-BY-NC-ND 4.0 International license .

https://doi.org/10.1053/crad.2000.0688

Dempsey, M.F., Condon, B., Hadley, D.M., 2001. Investigation of the factors responsible for burns during MRI. J. Magn. Reson. Imaging 13, 627-631. https://doi.org/10.1002/jmri.1088

Durand, S., Fromy, B., Bouyé, P., Saumet, J.L., Abraham, P., 2002. Vasodilatation in response to repeated anodal current application in the human skin relies on aspirin-sensitive mechanisms. J. Physiol. 540, 261-269. https://doi.org/10.1113/jphysiol.2001.013364

Dutta, A., Jacob, A., Chowdhury, S.R., Das, A., Nitsche, M.A., 2015. EEG-NIRS Based Assessment of Neurovascular Coupling During Anodal Transcranial Direct Current Stimulation - a Stroke Case Series. J. Med. Syst. 39. https://doi.org/10.1007/s10916-015-0205-7

Esmaeilpour, Z., Shereen, A.D., Ghobadi-Azbari, P., Datta, A., Woods, A.J., Ironside, M., O'Shea, J., Kirk, U., Bikson, M., Ekhtiari, H., 2019. Methodology for tDCS integration with fMRI. Hum. Brain Mapp. https://doi.org/10.1002/hbm.24908

Fleiss, J.L., 1971. Measuring nominal scale agreement among many raters. Psychol. Bull. 76, 378382. https://doi.org/10.1037/h0031619

Frangou, P., Correia, M., Kourtzi, Z., 2018. GABA, not BOLD, reveals dissociable learning-dependent plasticity mechanisms in the human brain. Elife 7. https://doi.org/10.7554/eLife.35854

Fricke, K., Seeber, A.A., Thirugnanasambandam, N., Paulus, W., Nitsche, M.A., Rothwell, J.C., 2011. Time course of the induction of homeostatic plasticity generated by repeated transcranial direct current stimulation of the human motor cortex. J. Neurophysiol. 105, 1141-1149. https://doi.org/10.1152/jn.00608.2009

Friedman, L., Glover, G.H., 2006. Report on a multicenter fMRI quality assurance protocol. J. Magn. Reson. Imaging. https://doi.org/10.1002/jmri.20583

Gbadeyan, O., Steinhauser, M., McMahon, K., Meinzer, M., 2016. Safety, Tolerability, Blinding Efficacy and Behavioural Effects of a Novel MRI-Compatible, High-Definition tDCS Set-Up. Brain Stimul. 9, 545-552. https://doi.org/10.1016/j.brs.2016.03.018

Ghobadi-Azbari, P., Jamil, A., Yavari, F., Esmaeilpour, Z., Malmir, N., Mahdavifar-Khayati, R., Soleimani, G., Cha, Y.-H., Shereen, A.D., Nitsche, M.A., Bikson, M., Ekhtiari, H., 2020. fMRI and Transcranial Electrical Stimulation (tES): A systematic review of parameter space and outcomes. medRxiv 2020.06.03.20121202. https://doi.org/10.1101/2020.06.03.20121202

Gilam, G., Abend, R., Gurevitch, G., Erdman, A., Baker, H., Ben-Zion, Z., Hendler, T., 2018. Attenuating anger and aggression with neuromodulation of the vmPFC: A simultaneous tDCSfMRI study. Cortex. 109, 156-170. https://doi.org/10.1016/j.cortex.2018.09.010

Göksu, C., Hanson, L.G., Siebner, H.R., Ehses, P., Scheffler, K., Thielscher, A., 2018. Human in-vivo brain magnetic resonance current density imaging (MRCDI). Neuroimage 171, 26-39. https://doi.org/10.1016/j.neuroimage.2017.12.075

Grainger, D., 2014. Safety Guidelines for Magnetic Resonance Imaging Equipment in Clinical Use.

Hsu, C.-C., Sandford, B.A., 2007. The Delphi Technique: Making Sense of Consensus, Practical Assessment, Research, and Evaluation.

Hu, J., Li, Y., Yin, Y., Blue, P.R., Yu, H., Zhou, X., 2017. How do self-interest and other-need interact in the brain to determine altruistic behavior? Neuroimage 157, 598-611.

Huang, Y., Datta, A., Bikson, M., Parra, L.C., 2019. Realistic volumetric-approach to simulate transcranial electric stimulation - ROAST - a fully automated open-source pipeline. J. Neural Eng. 16. https://doi.org/10.1088/1741-2552/ab208d

Jamil, A., Batsikadze, G., Kuo, H.I., Meesen, R.L.J., Dechent, P., Paulus, W., Nitsche, M.A., 2020. 
medRxiv preprint doi: https://doi.org/10.1101/2020.12.23.20248579; this version posted December 30, 2020. The copyright holder for this preprint (which was not certified by peer review) is the author/funder, who has granted medRxiv a license to display the preprint in It is made available under a CC-BY-NC-ND 4.0 International license .

Current intensity- and polarity-specific online and aftereffects of transcranial direct current stimulation: An fMRI study. Hum. Brain Mapp. 41, 1644-1666. https://doi.org/10.1002/hbm.24901

Kanai, R., Chaieb, L., Antal, A., Walsh, V., Paulus, W., 2008. Frequency-Dependent Electrical Stimulation of the Visual Cortex. Curr. Biol. 18, 1839-1843. https://doi.org/10.1016/j.cub.2008.10.027

Keeney, S., Hasson, F., McKenna, H.P., 2001. A critical review of the Delphi technique as a research methodology for nursing. Int. J. Nurs. Stud. 38, 195-200. https://doi.org/10.1016/S00207489(00)00044-4

Keeser, D., Meindl, T., Bor, J., Palm, U., Pogarell, O., Mulert, C., Brunelin, J., Möller, H.-J., Reiser, M., Padberg, F., 2011. Prefrontal transcranial direct current stimulation changes connectivity of resting-state networks during fMRI. J. Neurosci. 31, 15284-15293.

Kleiner, M., Brainard, D., Pelli, D., Ingling, A., Murray, R., Broussard, C., Cornelissen, F., 2007. What's new in Psychtoolbox-3? A free cross-platform toolkit for Psychophysics with Matlab \& GNU/Octave.

Koolschijn, R.S., Emir, U.E., Pantelides, A.C., Nili, H., Behrens, T.E.J., Barron, H.C., 2019. The Hippocampus and Neocortical Inhibitory Engrams Protect against Memory Interference. Neuron 101, 528-541.e6. https://doi.org/10.1016/j.neuron.2018.11.042

Kozlov, M., Horner, M., Kainz, W., Weiskopf, N., Möller, H.E., 2020. Modeling radio-frequency energy-induced heating due to the presence of transcranial electric stimulation setup at 3T. Magn. Reson. Mater. Physics, Biol. Med. 1-15. https://doi.org/10.1007/s10334-020-00853-5

Kozlov, M., Müller, R., Pampel, A., Kalloch, B., Weiskopf, N., Möller, H.E., 2018. RF safety of transcranial direct current stimulation equipment during MRI.

Kuo, M.-F., Polanía, R., Nitsche, M., 2016. Physiology of Transcranial Direct and Alternating Current Stimulation, in: Transcranial Direct Current Stimulation in Neuropsychiatric Disorders. Springer International Publishing, Cham, pp. 29-46. https://doi.org/10.1007/978-3-319-33967-2_3

Landis, J.R., Koch, G.G., 1977. The Measurement of Observer Agreement for Categorical Data. Biometrics 33, 159. https://doi.org/10.2307/2529310

Lee, D., Mahon, B.Z., Almeida, J., 2019. Action at a distance on object-related ventral temporal representations. Cortex 117, 157-167. https://doi.org/10.1016/j.cortex.2019.02.018

Lefebvre, S., Jann, K., Schmiesing, A., Ito, K., Jog, M., Schweighofer, N., Wang, D.J.J., Liew, S.L., 2019. Differences in high-definition transcranial direct current stimulation over the motor hotspot versus the premotor cortex on motor network excitability. Sci. Rep. 9, 1-15. https://doi.org/10.1038/s41598-019-53985-7

Lemieux, L., Allen, P.J., Franconi, F., Symms, M.R., Fish, D.R., 1997. Recording of EEG during fMRI experiments: Patient safety. Magn. Reson. Med. 38, 943-952. https://doi.org/10.1002/mrm.1910380614

Li, L.M., Violante, I.R., Leech, R., Hampshire, A., Opitz, A., McArthur, D., Carmichael, D.W., Sharp, D.J., 2019a. Cognitive enhancement with Salience Network electrical stimulation is influenced by network structural connectivity. Neuroimage 185, 425-433. https://doi.org/10.1016/j.neuroimage.2018.10.069

Li, L.M., Violante, I.R., Leech, R., Ross, E., Hampshire, A., Opitz, A., Rothwell, J.C., Carmichael, D.W., Sharp, D.J., 2019b. Brain state and polarity dependent modulation of brain networks by transcranial direct current stimulation. Hum. Brain Mapp. 40, 904-915. https://doi.org/10.1002/hbm.24420 
medRxiv preprint doi: https://doi.org/10.1101/2020.12.23.20248579; this version posted December 30, 2020. The copyright holder for this preprint (which was not certified by peer review) is the author/funder, who has granted medRxiv a license to display the preprint in It is made available under a CC-BY-NC-ND 4.0 International license .

Ligneul, R., Obeso, I., Ruff, C.C., Dreher, J.-C., 2016. Dynamical Representation of Dominance Relationships in the Human Rostromedial Prefrontal Cortex. Curr. Biol. 26, 3107-3115.

Lin, R.L., Douaud, G., Filippini, N., Okell, T.W., Stagg, C.J., Tracey, I., 2017. Structural Connectivity Variances Underlie Functional and Behavioral Changes During Pain Relief Induced by Neuromodulation. Sci. Rep. 7, 41603. https://doi.org/10.1038/srep41603

Marshall, T.R., Esterer, S., Herring, J.D., Bergmann, T.O., Jensen, O., 2016. On the relationship between cortical excitability and visual oscillatory responses - A concurrent tDCS-MEG study. Neuroimage 140, 41-49. https://doi.org/10.1016/j.neuroimage.2015.09.069

Matsunaga, K., Nitsche, M.A., Tsuji, S., Rothwell, J.C., 2004. Effect of transcranial DC sensorimotor cortex stimulation on somatosensory evoked potentials in humans. Clin. Neurophysiol. 115, 456-460. https://doi.org/10.1016/S1388-2457(03)00362-6

Meeker, T.J., Keaser, M.L., Khan, S.A., Gullapalli, R.P., Seminowicz, D.A., Greenspan, J.D., 2019. Noninvasive motor cortex neuromodulation reduces secondary hyperalgesia and enhances activation of the descending pain modulatory network. Front. Neurosci. 13, 467. https://doi.org/10.3389/fnins.2019.00467

Meinzer, M., Lindenberg, R., Antonenko, D., Flaisch, T., Floel, A., 2013. Anodal transcranial direct current stimulation temporarily reverses age-associated cognitive decline and functional brain activity changes. J. Neurosci. 33, 12470-12478. https://doi.org/10.1523/JNEUROSCI.574312.2013

Meinzer, M., Lindenberg, R., Darkow, R., Ulm, L., Copland, D., Floel, A., 2014. Transcranial direct current stimulation and simultaneous functional magnetic resonance imaging. J. Vis. Exp. https://doi.org/10.3791/51730

Minhas, P., Bansal, V., Patel, J., Ho, J.S., Diaz, J., Datta, A., Bikson, M., 2010. Electrodes for highdefinition transcutaneous DC stimulation for applications in drug delivery and electrotherapy, including tDCS. J. Neurosci. Methods 190, 188-197. https://doi.org/10.1016/j.jneumeth.2010.05.007

Misselhorn, J., Schwab, B.C., Schneider, T.R., Engel, A.K., 2019. Synchronization of sensory gamma oscillations promotes multisensory communication. eNeuro 6. https://doi.org/10.1523/ENEURO.0101-19.2019

Mizuguchi, N., Uehara, S., Hirose, S., Yamamoto, S., Naito, E., 2016. Neuronal Substrates Underlying Performance Variability in Well-Trained Skillful Motor Task in Humans. Neural Plast. 2016, 1245259. https://doi.org/10.1155/2016/1245259

Moisa, M., Pohmann, R., Ewald, L., Thielscher, A., 2009. New coil positioning method for interleaved transcranial magnetic stimulation (TMS)/functional MRI (fMRI) and its validation in a motor cortex study. J. Magn. Reson. Imaging 29, 189-197. https://doi.org/10.1002/jmri.21611

Moisa, M., Polania, R., Grueschow, M., Ruff, C.C., 2016. Brain Network Mechanisms Underlying Motor Enhancement by Transcranial Entrainment of Gamma Oscillations. J. Neurosci. 36, 12053-12065. https://doi.org/10.1523/JNEUROSCI.2044-16.2016

Monte-Silva, K., Kuo, M.F., Hessenthaler, S., Fresnoza, S., Liebetanz, D., Paulus, W., Nitsche, M.A., 2013. Induction of late LTP-like plasticity in the human motor cortex by repeated non-invasive brain stimulation. Brain Stimul. 6, 424-432. https://doi.org/10.1016/j.brs.2012.04.011

Nichols, T.E., Das, S., Eickhoff, S.B., Evans, A.C., Glatard, T., Hanke, M., Kriegeskorte, N., Milham, M.P., Poldrack, R.A., Poline, J.B., Proal, E., Thirion, B., Van Essen, D.C., White, T., Yeo, B.T.T., 2017. Best practices in data analysis and sharing in neuroimaging using MRI. Nat. Neurosci. https://doi.org/10.1038/nn.4500 
medRxiv preprint doi: https://doi.org/10.1101/2020.12.23.20248579; this version posted December 30, 2020. The copyright holder for this preprint (which was not certified by peer review) is the author/funder, who has granted medRxiv a license to display the preprint in It is made available under a CC-BY-NC-ND 4.0 International license.

Nihonsugi, T., Ihara, A., Haruno, M., 2015. Selective increase of intention-based economic decisions by noninvasive brain stimulation to the dorsolateral prefrontal cortex. J. Neurosci. 35, 34123419. https://doi.org/10.1523/JNEUROSCI.3885-14.2015

Nitsche, M.A., Liebetanz, D., Antal, A., Lang, N., Tergau, F., Paulus, W., 2003. Chapter 27 Modulation of cortical excitability by weak direct current stimulation - technical, safety and functional aspects. Suppl. Clin. Neurophysiol. 56, 255-276. https://doi.org/10.1016/S1567$424 \mathrm{X}(09) 70230-2$

Nitsche, M.A., Paulus, W., 2001. Sustained excitability elevations induced by transcranial DC motor cortex stimulation in humans Sustained excitability elevations induced by transcranial DC motor cortex stimulation in. Neurology 57, 1899-1901. https://doi.org/10.1212/WNL.57.10.1899

Nitsche, M.A., Paulus, W., 2000. Excitability changes induced in the human motor cortex by weak transcranial direct current stimulation. J. Physiol. 527 Pt 3, 633-9. https://doi.org/10.1111/J.1469-7793.2000.T01-1-00633.X

Padberg, F., Kumpf, U., Mansmann, U., Palm, U., Plewnia, C., Langguth, B., Zwanzger, P., Fallgatter, A., Nolden, J., Burger, M., Keeser, D., Rupprecht, R., Falkai, P., Hasan, A., Egert, S., Bajbouj, M., 2017. Prefrontal transcranial direct current stimulation (tDCS) as treatment for major depression: study design and methodology of a multicenter triple blind randomized placebo controlled trial (DepressionDC). Eur. Arch. Psychiatry Clin. Neurosci. 267, 751-766. https://doi.org/10.1007/s00406-017-0769-y

Palm, U., Feichtner, K.B., Hasan, A., Gauglitz, G., Langguth, B., Nitsche, M.A., Keeser, D., Padberg, F., 2014. The role of contact media at the skin-electrode interface during transcranial direct current stimulation (tDCS). Brain Stimul. https://doi.org/10.1016/j.brs.2014.06.006

Panych, L.P., Madore, B., 2018. The physics of MRI safety. J. Magn. Reson. Imaging. https://doi.org/10.1002/jmri.25761

Paus, T., 2005. Inferring causality in brain images: a perturbation approach. Philos. Trans. R. Soc. Lond. B. Biol. Sci. 360, 1109-14. https://doi.org/10.1098/rstb.2005.1652

Poldrack, R.A., Fletcher, P.C., Henson, R.N., Worsley, K.J., Brett, M., Nichols, T.E., 2008. Guidelines for reporting an fMRI study. Neuroimage. https://doi.org/10.1016/j.neuroimage.2007.11.048

Ruttorf, M., Kristensen, S., Schad, L.R., Almeida, J., 2019. Transcranial Direct Current Stimulation Alters Functional Network Structure in Humans: A Graph Theoretical Analysis. IEEE Trans. Med. Imaging 38, 2829-2837. https://doi.org/10.1109/TMI.2019.2915206

Saiote, C., Turi, Z., Paulus, W., Antal, A., 2013. Combining functional magnetic resonance imaging with transcranial electrical stimulation. Front. Hum. Neurosci. 7, 435. https://doi.org/10.3389/fnhum.2013.00435

Saturnino, G.B., Antunes, A., Thielscher, A., 2015. On the importance of electrode parameters for shaping electric field patterns generated by tDCS. Neuroimage 120, 25-35. https://doi.org/10.1016/j.neuroimage.2015.06.067

Schneider, W., Eschman, A., Zuccolotto, A., 2002. E-Prime reference guide.

Sehm, B., Kipping, J., Schäfer, A., Villringer, A., Ragert, P., 2013. A comparison between uni-and bilateral tDCS effects on functional connectivity of the human motor cortex. Front. Hum. Neurosci. 7.

Sehm, B., Schafer, A., Kipping, J., Margulies, D., Conde, V., Taubert, M., Villringer, A., Ragert, P., 2012. Dynamic modulation of intrinsic functional connectivity by transcranial direct current stimulation. J. Neurophysiol. 108, 3253-3263. https://doi.org/10.1152/jn.00606.2012 
medRxiv preprint doi: https://doi.org/10.1101/2020.12.23.20248579; this version posted December 30, 2020. The copyright holder for this preprint (which was not certified by peer review) is the author/funder, who has granted medRxiv a license to display the preprint in It is made available under a CC-BY-NC-ND 4.0 International license.

Shellock, F.G., Woods, T.O., Crues, J. V., 2009. MR labeling information for implants and devices: Explanation of terminology. Radiology. https://doi.org/10.1148/radiol.2531091030

Stagg, C.J., Nitsche, M.A., 2011. Physiological Basis of Transcranial Direct Current Stimulation. Neurosci. 17, 37-53.

Thielscher, A., Antunes, A., Saturnino, G.B., 2015. Field modeling for transcranial magnetic stimulation: A useful tool to understand the physiological effects of TMS?, in: Proceedings of the Annual International Conference of the IEEE Engineering in Medicine and Biology Society, EMBS. Institute of Electrical and Electronics Engineers Inc., pp. 222-225. https://doi.org/10.1109/EMBC.2015.7318340

Turi, Z., Ambrus, G.G., Janacsek, K., Emmert, K., Hahn, L., Paulus, W., Antal, A., 2013. Both the cutaneous sensation and phosphene perception are modulated in a frequency-specific manner during transcranial alternating current stimulation. Restor. Neurol. Neurosci. 31, 275-285. https://doi.org/10.3233/RNN-120297

Vernon, W., Vernon, W., 2009. The Delphi technique: A review. Int. J. Ther. Rehabil. 16, 69-76. https://doi.org/10.12968/ijtr.2009.16.2.38892

Violante, I.R., Li, L.M., Carmichael, D.W., Lorenz, R., Leech, R., Hampshire, A., Rothwell, J.C., Sharp, D.J., 2017. Externally induced frontoparietal synchronization modulates network dynamics and enhances working memory performance. Elife 6. https://doi.org/10.7554/eLife.22001

Vosskuhl, J., Huster, R.J., Herrmann, C.S., 2016. BOLD signal effects of transcranial alternating current stimulation (tACS) in the alpha range: A concurrent tACS-fMRI study. Neuroimage 140, 118-125. https://doi.org/10.1016/j.neuroimage.2015.10.003

Wang, Y., Ma, N., He, X., Li, N., Wei, Z., Yang, L., Zha, R., Han, L., Li, X., Zhang, D. \%J N., 2017. Neural substrates of updating the prediction through prediction error during decision making 157, 112.

Williams, K.A., Cabral-Calderin, Y., Schmidt-Samoa, C., Weinrich, C.A., Dechent, P., Wilke, M., 2017. Simultaneous Transcranial Alternating Current Stimulation and Functional Magnetic Resonance Imaging. J. Vis. Exp. https://doi.org/10.3791/55866

Woods, A.J., Antal, A., Bikson, M., Boggio, P.S., Brunoni, A.R., Celnik, P., Cohen, L.G., Fregni, F., Herrmann, C.S., Kappenman, E.S., Knotkova, H., Liebetanz, D., Miniussi, C., Miranda, P.C., Paulus, W., Priori, A., Reato, D., Stagg, C., Wenderoth, N., Nitsche, M.A., 2016. A technical guide to tDCS, and related non-invasive brain stimulation tools. Clin. Neurophysiol. 127, 1031-1048. https://doi.org/10.1016/j.clinph.2015.11.012

Woods, A.J., Hamilton, R.H., Kranjec, A., Minhaus, P., Bikson, M., Yu, J., Chatterjee, A., 2014. Space, time, and causality in the human brain. Neuroimage 92, 285-297.

Wu, Q., Chang, C., Xi, S., Huang, I., Liu, Z., Juan, C., Wu, Y., Fan, J., 2015. A critical role of temporoparietal junction in the integration of top-down and bottom-up attentional control. Hum. Brain Mapp. 36, 4317-4333.

Xue, G., Juan, C.-H., Chang, C.-F., Lu, Z.-L., Dong, Q., 2012. Lateral prefrontal cortex contributes to maladaptive decisions. Proc. Natl. Acad. Sci. U. S. A. 109, 4401-4406. https://doi.org/10.1073/pnas.1111927109

Yang, L.-Z., Shi, B., Li, H., Zhang, W., Liu, Y., Wang, H., Zhou, Yanfei, Wang, Y., Lv, W., Ji, X., Hudak, J., Zhou, Yifeng, Fallgatter, A.J., Zhang, X., 2017. Electrical stimulation reduces smokers' craving by modulating the coupling between dorsal lateral prefrontal cortex and parahippocampal gyrus. Soc. Cogn. Affect. Neurosci. 12, 1296-1302. https://doi.org/10.1093/scan/nsx055

Zhang, Y., Yu, H., Yin, Y., Zhou, X., 2016. Intention Modulates the Effect of Punishment Threat in 
medRxiv preprint doi: https://doi.org/10.1101/2020.12.23.20248579; this version posted December 30, 2020. The copyright holder for this preprint (which was not certified by peer review) is the author/funder, who has granted medRxiv a license to display the preprint in It is made available under a CC-BY-NC-ND 4.0 International license

Norm Enforcement via the Lateral Orbitofrontal Cortex. J. Neurosci. 36, 9217-9226.

Zoefel, B., Archer-Boyd, A., Davis, M.H., 2018. Phase Entrainment of Brain Oscillations Causally Modulates Neural Responses to Intelligible Speech. Curr. Biol. 28, 401-408.e5. https://doi.org/10.1016/j.cub.2017.11.071 